\title{
A Dynamic Model of Speech for the Social Sciences
}

\section{DEAN KNOX University of Pennsylvania CHRISTOPHER LUCAS Washington University in St. Louis}

\begin{abstract}
Speech and dialogue are the heart of politics: nearly every political institution in the world involves verbal communication. Yet vast literatures on political communication focus almost exclusively on what words were spoken, entirely ignoring how they were delivered-auditory cues that convey emotion, signal positions, and establish reputation. We develop a model that opens this information to principled statistical inquiry: the model of audio and speech structure (MASS). Our approach models political speech as a stochastic process shaped by fixed and time-varying covariates, including the history of the conversation itself. In an application to Supreme Court oral arguments, we demonstrate how vocal tone signals crucial information-skepticism of legal arguments - that is indecipherable to text models. Results show that justices do not use questioning to strategically manipulate their peers but rather engage sincerely with the presented arguments. Our easy-to-use R package, communication, implements the model and many more tools for audio analysis.
\end{abstract}

\begin{abstract}
What we say can sometimes ... be challenging for the sake of eliciting a response, sometimes it can be genuine doubt about what the position of a person might be, sometimes we're talking to each other and we're raising points through the questions that we want our colleagues to consider with us ... there's lots of reasons for what we're doing, but none of them are ever perfectly understood ... among the people who are listening.
\end{abstract}

-Sotomayor (2019)

Dean Knox (D), Faculty Fellow of Analytics at Wharton, and Assistant Professor, The Wharton School of the University of Pennsylvania,dcknox@upenn.edu.

Christopher Lucas (D), Assistant Professor, Department of Political Science, Washington University in St. Louis, christopher.lucas@ wustl.edu.

For excellent research assistance, we thank Taylor Damann. For helpful comments, we thank Justin de Benedictis-Kessner, Josh Boston, Bryce Dietrich, J. B. Duck-Mayr, Seth Hill, Luke Keele, Gary King, Connor Huff, In Song Kim, Adeline Lo, Andrew Martin, Jacob Montgomery, Jonathan Mummolo, David Romney, Jake Shapiro, Brandon Stewart, Dustin Tingley, Michelle Torres, Ariel White, Teppei Yamamoto, and Xiang Zhou, as well as participants at the Harvard Applied Statistics Workshop, the Princeton Quantitative Social Science Colloquium, the International Methods Colloquium, the Texas Political Methodology Conference, and the Washington University in St. Louis Political Data Science Lab. Dean Knox gratefully acknowledges financia support from Analytics at Wharton; the Schmidt DataX Fund at Princeton University, made possible through a major gift from the Schmidt Futures Foundation; the Microsoft Research Computational Social Science postdoctoral researcher program; and the National Science Foundation (Graduate Research Fellowship under Grant No. 1122374). Christopher Lucas gratefully acknowledges his Dean's support for this project. Replication files are available at the American Political Science Review Dataverse: https: //doi.org/10.7910/DVN/8BTOHQ.

Received: May 10, 2019; revised: October 27, 2020; accepted: October 29, 2020. First published online: March 2, 2021.

\section{INTRODUCTION}

$\mathrm{S}^{\mathrm{c}}$ peech and dialogue are at the heart of politics. Candidates appeal to voters through rhetoric, legislators contest policy during floor debates, courts probe legal argumentation with questioning, and voters discuss all of these with friends and family. Indeed, nearly every political institution in the world, from small-town councils to the United Nations General Assembly, involves verbal communication. Yet quantitative political science has only just begun to analyze political speech-and when it does, analysts have done so with the tools of text analysis. While fruitful, these methods entirely ignore the way in which words are spoken.

This channel of communication, vocal tone, carries a wealth of unexploited information. In the next section, we explain how tone is used by listeners to assess speakers' types and mental states. When politicians express themselves skeptically, compassionately, or fervently, their speech conveys more than the mere words that are spoken. Among other information, tone conveys beliefs, preferences, and the intensity with which they are held-or at least, the impressions of these characteristics that the speaker hopes to leave on their audience. The role of voice in persuading others be they colleagues, adversaries, or electorates - to do what they would not otherwise do has been known at least since Aristotle's On Rhetoric. Perhaps surprisingly, audio recordings are already widely available and have been used in literatures spanning political debates, campaign advertisements, campaign speech, legislative speech, television news, talk radio, and judicial deliberation. But almost universally, researchers have studied this data by extracting mere textual transcripts, then discarding the vast amount of untapped data that remains. In this paper, we introduce a new method that allows researchers to not only measure vocal tone in high-dimensional audio data but also study how it is used in political interactions. 
Given the ubiquity of verbal communication in politics, why are models of speech only now being introduced? In this paper, we identify and resolve three challenges to the widespread analysis of speech audio. First, speech audio recordings do not naturally arrive in a format that is easy to analyze statistically. In "Audio as Data," we demonstrate how audio recordings of speech can be represented numerically, drawing on insights from signal processing and linguistics. Second, the theoretically interesting quantities signaled by human speech - which may range from basic emotions (e.g., anger) to abstract concepts (e.g., decisiveness), depending on substantive domain - are latent variables that are not directly observed in audio data but must be inferred. In "A Model of Conversation Dynamics," we address this by developing a semisupervised model for human speech, which infers latent tones of voice and provides a principled measure of uncertainty for the estimated patterns in their use. Third, speech is inherently context-dependent-theories suggest that candidates' vocal tone may vary depending on their position in the polls or the topic at hand-and dynamic, with back-and-forth interaction between speakers. In dialogues like political debates or media interviews, an interruption by one person may be met with a polite but firm response, whereas a different interjection could produce an angry retort. We refer to these and other temporal patterns in the choice of tone as the flow of speech. Interdependence is often treated as a nuisance or ignored entirely, but we show that speech flow is a valuable source of information about human interaction. By directly modeling this phenomenon, new substantive questions about dynamic interactions are opened to principled statistical inquiry.

In "Testing Theories of Supreme Court Deliberation," we demonstrate that speech tone and flow are substantively important by resolving an ongoing debate in the study of the Supreme Court. Judicial scholars have long disagreed over models of justice behavior in deliberation; some argue that justices are shrewd political actors who maneuver to influence the decisions of their peers, while others hold that justices cast sincere votes and engage in genuine expression according to their respective legal philosophies. We measure and extensively validate a key auditory quantity of interest that is unmeasurable with only the text of speech: skepticism, an individual's vocal expression of their judgment about an assertion or argument. Existing theories suggest diverging observable implications for the expected flow of questioning - when one justice should express skepticism and how other subsequent justices should respond in their own speech - which we use to construct previously infeasible empirical tests of judicial behavior. We find that estimated flow is highly consistent with a theory of genuine fact-finding, and it undermines the competing account of strategic manipulation. We then conclude by noting several open areas of research highlighted by this manuscript.

\section{THE IMPORTANCE OF AUDIO}

It is well-known that vocal tone plays an important role in human communication, beyond a speaker's choice of words. In this section, we review evidence that listeners extract considerable information from vocal tone, drawing on numerous studies in linguistics and psychology. We then identify a wide range of literatures in political science that currently study rich speech recordings using textual methods alone, ignoring the auditory component. Taken together, these points suggest that political science is currently missing a great deal by discarding the raw source audio. We briefly note a handful of the many possible applications in which our speech model can help test existing and new theories about political deliberation.

\section{Audio Contains Exclusive Information}

Tens of thousands of studies have decisively established the importance of nontextual cues in human speech. ${ }^{1}$ Among other well-replicated results, they have shown that respondents' perceptions - including dehumanization of those with opposing political views (Schroeder and Epley 2016) - differ dramatically when exposed to audio recordings of speech, as opposed to transcripts alone. Countless experiments in linguistics and psychology have explored specific auditory mechanisms through which a speaker's voice shapes the information gleaned by listeners on numerous dimensions. Speech audio has been shown to convey information about speakers' static type (e.g., power), as well as their time-varying characteristics (e.g., emotional state). We briefly review this literature.

\section{Signals of a Speaker's Type}

Much is inferred about a speaker simply from the general sound of their voice. Humans use vocal tone to draw conclusions about competence, education, and trustworthiness, among many other attributes (Anderson et al. 2014; Zuckerman and Driver 1989). In the political domain, both observational and experimental research has shown that voters' preferences are affected by the sound of a candidate's voice (Gregory and Gallagher 2002; Klofstad 2016; Klofstad, Anderson, and Peters 2012; Podesva et al. 2015; Surawski and Ossoff 2006; Tigue et al. 2012). This effect is mediated, at least in part, by the belief that certain speaking styles are associated with strong, dominant leaders who are more likely to prevail in conflict (Klofstad, Anderson, and Nowicki 2015; Laustsen, Petersen, and Klofstad 2015). These patterns appear to generalize well across a range of political roles (Anderson and Klofstad 2012), building on well-established findings in psychology that nontextual elements of human conversation shift perceptions of speakers' social power (Carney, Hall, and LeBeau 2005; Hodges-Simeon, Gaulin, and Puts 2010;

\footnotetext{
${ }^{1}$ A Google Scholar search for "paralinguistic" returned over 68,000 results in 2020 .
} 
Scherer, London, and Wolf 1973), credibility, persuasiveness (Apple, Streeter, and Krauss 1979; Burgoon, Birk, and Pfau 1990; Hamilton and Stewart 1993), and intelligence (Brown, Strong, and Rencher 1974; Schroeder and Epley 2015; Smith et al. 1975). These results suggest that the way in which individuals speak reveals, at a minimum, how they wish to be perceived by their audiences. For example, Touati (1993) found that a politician's pitch contour was more variable before an election and monotonic after, suggesting a pre-election desire to signal attributes like competence that are associated with this vocal tone.

In political science, research on debates has shown that the way politicians express themselves matters. Hinck and Hinck $(2002,236)$ argue that audiences scrutinize rhetoric for "politeness strategies" that are used to "measure a candidate's good will and judgment regarding his image, his opponent's, and the values he aspires to represent for the community." Evidence from real-time voter reactions suggests that overly aggressive attacks can lead to immediate drops in ratings (McKinney, Kaid, and Robertson 2001). The instantaneous effect of utterances depends on factors like audience composition (Boydstun et al. 2014), implying politicians may benefit by presenting themselves differently depending on context. In this vein, scholars such as Benoit, Blaney, and Pier (1998) have advanced contextualized theories of rhetoric indicating when candidates should attack, defend, or self-acclaim across a campaign - not only in debates but also in speeches and advertisements; Brader (2006) provides evidence that politicians selectively target emotional appeals based on context-specific expected benefits. Still others have posited that conversational flow plays a particularly important role in voter evaluations. Discussing debates, town halls, and talk show appearances, Beck (1996) asserts that to be perceived as presidential, "candidates must project themselves as able to cope and excel in spite of conflict over issues and despite their opponents' attempts to define them," and that success "hinges on their interactional skills, not just their ability to look a certain way or say particular things." Nor does the role of rhetoric diminish after election: a broad literature on "going public" (Kernell, 2006) explores how presidents increasingly make televised appeals directly to the public. However, work on political rhetoric has largely relied on qualitative methods or labor-intensive human coding due to the difficulty of empirical analysis - a gap that our method directly addresses.

\section{Signals of a Speaker's Current State}

Speech signals much more than "presidentialness" or other time-invariant characteristics. Temporal variation in vocal tone can also indicate the mental state - such as emotions or impressions (Banse and Scherer 1996; Johnstone and Scherer 2000; Kappas, Hess, and Scherer 1991; Scherer 1995; Scherer, Koivumaki, and Rosenthal 1972)-that a speaker currently wishes to convey. Some of this variation has subconscious biological origins. Certain emotional states produce physiological effects such as mouth dryness, accelerated breathing, muscular tension, or tremors (Ohala 1981), which have audible effects on speech, though practiced speakers like actors and politicians can consciously emulate these unconscious effects. ${ }^{2}$ Vocal mannerisms also convey a speaker's current impressions of a conversation, such as their level of certainty, understanding, agreement, and belief (Manusov and Trees 2002). These vocal cues form an important part of the dynamic interplay between speakers in a conversation (Leathers 1979).

In "Testing Theories of Supreme Court Deliberation," we build on this work by studying one particular time-varying speech tone justices' expressed skepticism. Skepticism is an important signal-perhaps genuine-of disagreement with or incredulity about assertions and legal arguments in the context of oral arguments. Patterns in the flow of conversation shed light on how justices deliberate, just as patterns of matter-of-fact questioning or righteous indignation in campaign debates and impeachment hearings can help reveal the nature of interactions in these political arenas. We show that different theoretical accounts of deliberation imply diverging temporal patterns in speech flow, allowing us to construct an empirical test for competing models of Supreme Court behavior.

Relatedly, speech audio can affect a listener's trust in the speaker (Schirmer et al. 2019; Zuckerman et al. 1979); specifically, the listener's suspicion that the speaker is lying (Manstead, Wagner, and MacDonald 1984; Zuckerman, DePaulo, and Rosenthal 1981). To our knowledge, no work has directly tested the effect of vocal tone on perceived deception by politicians. Given the importance of credibility in conflict (Fearon 1994; Guisinger and Smith 2002) and trust in elections (Hetherington 1999; Levi and Stoker 2000), this relationship warrants future investigation. However, research has firmly established that these time-varying signals play an important role elsewhere in politics. For example, Dietrich, Enos, and Sen (2019) demonstrated that the average pitch of Supreme Court justice questions is predictive of their subsequent votes, even after controlling for text, important legal covariates, and justice ideology (Martin and Quinn 2002). Similarly, the average pitch of a legislator's floor speech has also been used to proxy for issue commitment (Dietrich, Hayes, and O'Brien 2019) and can predict coverage on cable news (Dietrich, Schultz, and Jaquith 2018).

\section{Political Science Already Studies Audio}

Audio recordings of speech are thus indisputably a rich source of data. But how often are these recordings available in contexts of interest to political scientists? We now demonstrate that the answer is "quite often." In fact, a wide range of research has already studied audio recordings of political speech-but in virtually

\footnotetext{
${ }^{2}$ Much research on emotion in speech relies on actors (Scherer 2003), a logical impossibility if emotional expression in speech was strictly subconscious.
} 
every domain, researchers have done so by extracting transcripts, then discarding the remainder of their data.

In "A New Quantity of Interest in Judicial Behavior," we consider one such domain. Here, published research has focused almost exclusively on the text of oral arguments (Black, Sorenson, and Johnson 2013; Kaufman, Kraft, and Sen 2018; Ringsmuth, Bryan, and Johnson 2013). ${ }^{3}$ For example, Black et al. (2011) examine how justices question parties in oral arguments, showing that text-based measures of affective questioning can signal voting decisions. In a direct comparison, we demonstrate that a comparable audiobased measure outperforms this prior work by three times, using its own evaluation task.

However, the Supreme Court is hardly the only context in which political scientists are already studying speech. Countless other studies have examined political debates (Bayley 2004; Benoit 2013; Conway et al. 2012; Fridkin et al. 2007; Hart and Jarvis 1997; Thomas, Pang, and Lee 2006), campaign advertisements (Carlson and Montgomery 2017; Fridkin and Kenney 2011; Spiliotes and Vavreck 2002), campaign speech (Bligh et al. 2010; Degani 2015; Laver, Benoit, and Garry 2003; Olson et al. 2012; Schroedel et al. 2013), legislative speech (Herzog and Benoit 2015; Lauderdale and Herzog 2016; Proksch and Slapin 2012; 2015; Quinn et al. 2010; Schwarz, Traber, and Benoit 2017; Slapin and Proksch 2008), television news (Behr and Iyengar 1985; Mermin 1997; Oegema and Kleinnijenhuis 2000; Rozenas and Stukal 2019; Sanders and Gavin 2004; Semetko and Valkenburg 2000; Young and Soroka 2012), talk radio (Conroy-Krutz and Moehler 2015; Hofstetter et al. 1999; Ross 2016; Sobieraj and Berry 2011), and political addresses (Cohen 1995; Ritter and Howell 2001; Rule, Cointet, and Bearman 2015; Young and Perkins 2005).

Each of these studies used text analysis to study a political context in which communication was not written and read as text, but rather was spoken and heard as audio. Given the relative youth of text analysis methods, it is perhaps surprising how often recorded speech is analyzed in this way. The mismatch between data and methods results in the inevitable loss of nontextual information, suggesting that richer models have the potential to contribute to research in each of these domains.

\section{AUDIO AS DATA}

The number of papers developing and applying methods for text analysis has increased rapidly in recent years (Wilkerson and Casas 2017), and workflows for preprocessing raw text are well developed (Benoit et al. 2018; Grimmer and Stewart 2013; Lucas et al. 2015). However, little effort has been devoted to the analysis of other components of communication-like audio - "as data." In this section, we explain how unstructured

\footnotetext{
${ }^{3}$ A notable exception is Dietrich, Enos, and Sen (2019), discussed above.
}

audio recordings of human speech can similarly be preprocessed into structured data in preparation for statistical analysis.

The primary unit of analysis in speech is the utterance: a continuous, single-speaker segment, typically concluding with a clear pause. The length of utterances are unequal but on the order of 10 seconds. Within each utterance, we split the recording into successive moments, or extremely short windows of time. ${ }^{4}$ In each moment, the raw audio is then summarized with auditory features that are known to convey emotion and tone of voice, drawing on established literatures in psychology, phonetics, signal processing, and computer science (El Ayadi, Kamel, and Karray 2011; Ververidis and Kotropoulos 2006). Researchers can easily calculate these features with a single function in our accompanying $\mathrm{R}$ package, communication, which also implements other useful preprocessing steps. ${ }^{5} \mathrm{We}$ briefly describe audio featurization to provide intuition. ${ }^{6}$

Within each moment, the raw audio recording consists of a waveform, or univariate high-frequency time series of pressure measurements. We characterize this short recording with auditory features describing the sound perceived by listeners. Selected features are illustrated in Figure 1 by describing an audio source for which a feature is high or low. For example, some features are simple functions of the raw waveform. One feature is the "zero crossing rate" (ZCR), or simply how often the waveform crosses zero (neutral pressure). Sibilants (e.g., $/ \mathrm{s} /$, , $\mathrm{z} /$ ) have a particularly high ZCR, whereas vowels have a low ZCR. Other auditory features, like "energy" (loudness), help distinguished /z/ (which is "voiced," i.e., involving vocal cord vibrations) from voiceless $/ \mathrm{s} /$.

Other features are based on the audio spectrum, computed via a Fourier transformation of the waveform. This captures (among other things) the contribution of the baritone or soprano ranges to overall loudness. Other undepicted features that can be computed from this representation include pitch (dominant frequency, or spectral peak) and Mel-frequency cepstral coefficients (MFCCs, describing overall shape). Because English words may be emphasized with higher sustained pitch or with sharp falling pitch, these features provide additional emotional information. For example, compare "We're citing that case?" to "We're citing that case!" Pitch is also higher when speakers are vocally tense, including when speakers are emotionally aroused. Online Appendix Section 2 documents all features used in analysis. In general, no single auditory feature distinguishes all sounds or vocal tones; to address this challenge, we develop a method that can exploit dozens or even hundreds of features in analyzing speech.

\footnotetext{
${ }^{4}$ We use windows that are 25 milliseconds in length, each overlapping the latter half of the previous moment (sometimes referred to as a "frame" or "window") to preserve information occurring at cutoffs. ${ }^{5}$ For instance, our package includes functionality for segmenting utterances or trimming interruptions.

${ }^{6}$ Online Appendix Section 5 briefly describes how communication improves on existing software.
} 
FIGURE 1. Illustration of Selected Audio Features

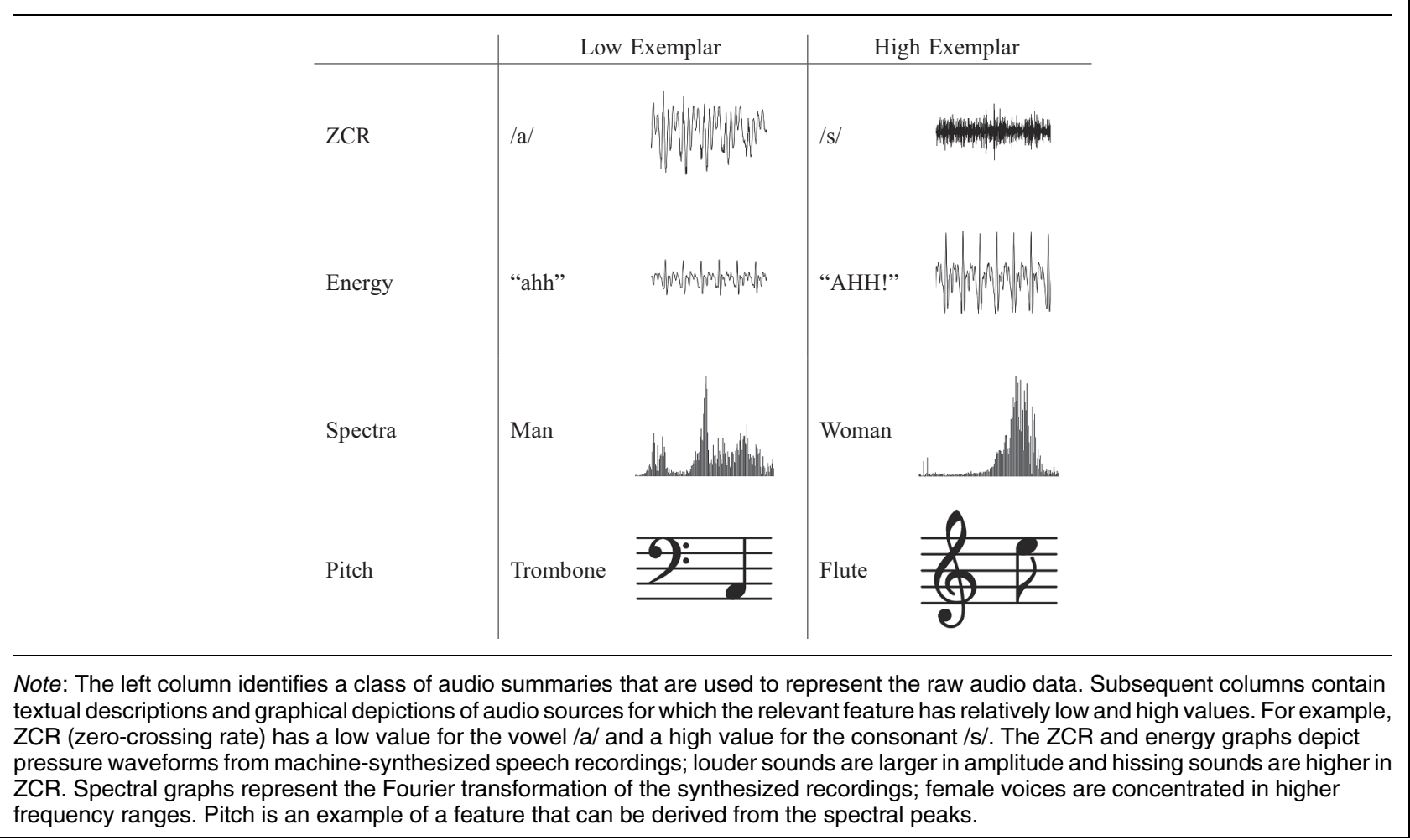

\section{Advances over Existing Approaches}

Outside of political science, a large and interdisciplinary body of research has sought to model or classify human speech. A common approach is to collapse each utterance into a vector of descriptive statistics (e.g., mean and standard deviation of pitch), which can be used in standard machine-learning classifiers (Dellaert, Polzin, and Waibel 1996; McGilloway et al. 2000). However, these reduced representations discard enormous amounts of auditory data. To avoid this loss of information, hidden Markov models are often used to model time-series speech. The discrete latent states in this model map well to actual human speech, which is often represented in terms of discrete phonemes, or minimal units of sound. ${ }^{7}$

The model of audio and speech structure (MASS) builds on these existing approaches in statistics and computer science in two main ways. First, computational constraints mean that typical analyses based on hidden Markov models (HMMs) are able to incorporate only a fraction of the features we incorporate. Nogueiras et al. (2001), for example, use just two features to represent a moment in time, while Kwon et al. (2003) use 13 features and Mower et al. (2009) use only the MFCC coefficients. Second, and more importantly, MASS is the first to directly model the flow of speech - that is, contextual and temporal patterns in vocal tone-in terms of the meaningful structural features encoded in conversation metadata.

\footnotetext{
${ }^{7}$ For example, the International Phonetic Alphabet identifies 107 discrete phonemes that are grouped into broader families like "fricatives" and "plosives."
}

\section{The Substantive Importance of Speech Flow}

Modeling the flow of speech permits principled empirical inquiry into a large and varied set of substantive questions about interaction between speakers. This enables the study of new questions and quantities of interest. For example, by modeling the dynamics of speech (i.e., change of flow in response to prior events), MASS allows researchers to ask and answer questions about how a line of argumentation affects downstream discourse. While these sorts of questions are common in theoretical models of sequential games (Dancey and Goren 2010; Ramirez 2009), they are rarely tested empirically. We suggest that this is due to the absence of a suitable empirical model, and "Testing Theories of Supreme Court Deliberation" demonstrates how MASS can answer questions of this sort.

\section{A MODEL OF CONVERSATION DYNAMICS}

We now develop a generative statistical model for the audio data that represents political speech. Below, we formally define the assumed generative model. After outlining the model, we next turn to estimation and inference, then discuss practical considerations in the modeling of speech.

\section{The Model}

Suppose we have a conversation with $U$ sequential utterances, each of which arises from one of $M$ modes of speech. (To keep the exposition clear, here we consider the simplified setting in which a single conversation 
FIGURE 2. Illustration of Generative Model

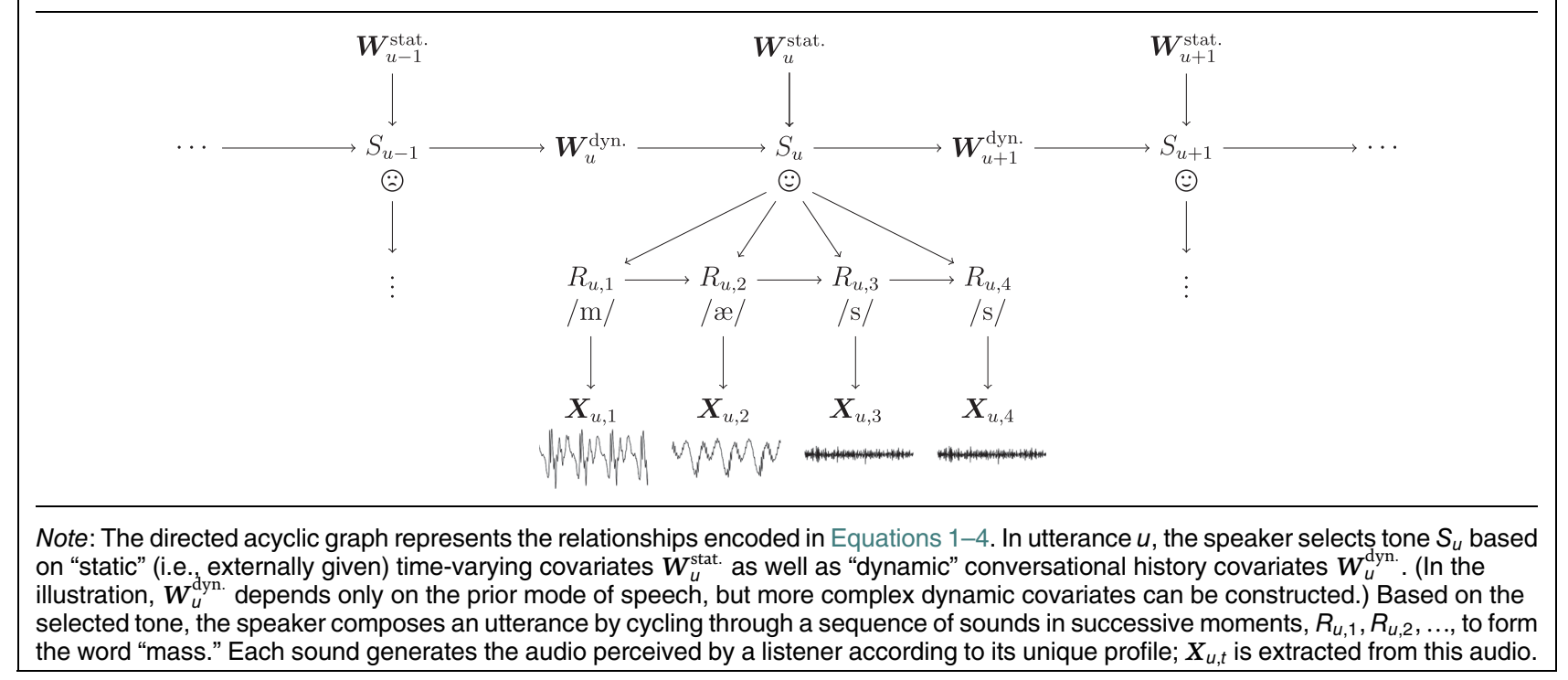

is analyzed. Online Appendix Section 1 presents the general multiconversation model, which is essentially identical.) Let $S_{u} \in\{1, \ldots, M\}$ denote the speech mode, or tone, of utterance $u \in\{1, \ldots, U\}$. Broadly, the model contains two levels. The "upper" level, defined in Equations 1-2, characterizes the flow of speech, or the choice of $S_{u}$. We assume that the conversation unfolds as a time-varying stochastic process in which $S_{u}$ is chosen based on the conversational context at that moment, encoded in the vector $\boldsymbol{W}_{u}$. In the "lower" level, we then outline a generative model for utterance $u$ 's auditory characteristics, $\boldsymbol{X}_{u}$. Importantly, this generative model will differ depending on the tone of voice selected in the upper model, $S_{u}$. Equations 3-4 present the lower level more formally. The model is summarized graphically in Figure 2, and we refer readers there for a holistic view of how the various model components fit together.

We begin by modeling speech mode probabilities in each utterance as a multinomial logistic function of conversational context, $\boldsymbol{W}_{u}$. Note that $\boldsymbol{W}_{u}$ may include functions of conversational history, such as aggregate anger expressed by previous speakers over the course of an argument - that is, $\sum_{u^{\prime}<u} 1\left(\boldsymbol{S}_{u^{\prime}}=\right.$ anger $)-$ which might induce a sharp retort in utterance $u$. These follow

$$
\begin{gathered}
\Delta_{u, m}=\exp \left(\boldsymbol{W}_{u}^{\top} \zeta_{m}\right) / \sum_{m^{\prime}=1}^{M} \exp \left(\boldsymbol{W}_{u}^{\top} \zeta_{m^{\prime}}\right) \text { and } \\
S_{u} \sim \operatorname{Cat}\left(\boldsymbol{\Delta}_{u}\right),
\end{gathered}
$$

where $\boldsymbol{\Delta}_{u}=\left[\Delta_{u, 1}, \ldots, \Delta_{u, M}\right]$ and $\zeta_{m}$ is a mode-specific coefficient vector through which $W_{u}$ affects the relative prevalence of mode $m$. The tone of utterance $u, S_{u}$, is one of the primary quantities of interest, along with the coefficients $\zeta_{m}$ that explain why certain tones are used more in particular contexts. However, generally speaking, tone is not directly observable to the analyst; the utterance's auditory characteristics, $\boldsymbol{X}_{u}$, are the only available information. (As we discuss in the following section, the analyst will begin estimation by obtaining a sample of utterances with human-labeled tone.)

Each $\boldsymbol{X}_{u}$ is a matrix describing the auditory characteristics of utterance $u$. In this matrix, the $t$-th row describes the audio at moment $t$ in terms of $D$ auditory features. Thus, the utterance audio is represented by a $T_{u} \times D$ feature matrix, where $T_{u}$ is the length of the utterance; because utterances may be of differing lengths, $\boldsymbol{X}_{u}$ and $\boldsymbol{X}_{u^{\prime}}$ may have differing numbers of rows.

To model the audio, we then assume that the $m$-th mode of speech is associated with its own Gaussian HMM that produces the auditory features as follows. At moment $t$ in utterance $u$, the speaker enunciates the sound $R_{u, t}$-that is, the latent state, which may represent phonemes or phoneme groups such as plosives or fricatives. In successive moments, the speaker alternates through these latent sounds according to

$$
\left(R_{u, t} \mid S_{u}=m\right) \sim \operatorname{Cat}\left(\Gamma_{R_{u, t-1}, *}^{m}\right),
$$

with $\Gamma_{k, *}^{m}$ denoting rows of the transition matrix, $\left[\operatorname{Pr}\left(R_{u, t}=1 \mid R_{u, t-1}=k\right), \ldots, \operatorname{Pr}\left(R_{u, t}=K \mid R_{u, t-1}=k\right)\right]$. By modeling the usage patterns of different sounds in this way, we approximately capture the temporal structure that plays an important role in speech. (For example, most latent sounds are sustained for at least a few moments, and certain phonemes typically occur before the silence at the end of a word.) In turn, latent sound $k$ is associated with its own auditory profile, which we operationalize as a multivariate Gaussian distribution with parameters $\boldsymbol{\mu}^{m, k}$ and $\Sigma^{m, k}$. Finally, the raw audio heard at moment $t$ of utterance $u$-the signal perceived by a listener-is drawn as

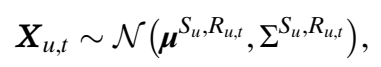

which completes the model. Thus, each mode of speech is represented with a rich and flexible HMM 


\section{TABLE 1. Observed and Unobserved Quantities}

\begin{tabular}{|c|c|c|c|c|}
\hline & Static metadata & Conversation history & Speech mode & Audio features \\
\hline Primary corpus & $W^{\text {stat., } \mathcal{C}}$ & $W^{\text {dyn., }, \mathcal{C}}$ & $S^{\mathcal{C}}$ & $\boldsymbol{X}^{\mathcal{C}}$ \\
\hline Training utterances & $W^{\text {stat., } \mathcal{T}}$ & $W^{\text {dyn., } \mathcal{T}}$ & $S^{\mathcal{T}}$ & $\boldsymbol{X}^{\mathcal{T}}$ \\
\hline
\end{tabular}

Note: Data that are (un)available to the analyst are (un)boxed. Attributes of the primary corpus (training set) are indicated with $\mathcal{C}(\mathcal{T}$ ) superscripts. Raw audio features, $\boldsymbol{X}$, are observed for all utterances. The portion of the conversational context that relates to static metadata ( $W^{\text {stat. }}$ ) is available for at least the primary corpus, but dynamic contextual variables that depend on the tone of prior utterances $\left(W^{\text {dyn. }}\right)$ can only be estimated. In general, the tone of each utterance $(S)$ is also unobserved, but the analyst possesses a small training set with human-labeled utterances.

that nevertheless reflects much of the known structure of human speech. It is the differences in usage patterns and sound profiles - the Gaussian HMM parameters that enable human listeners to distinguish one tone or speaker from another.

\section{Estimation}

We describe a procedure for estimating the model defined above, incorporating elements of both unsupervised and supervised learning. The researcher begins by determining the speech modes of interest, then identifying and labeling example utterances from each class. Within this training set-which might not be a subset of the primary corpus of interest - we consider each mode of speech in turn, using a fully unsupervised approach to learn the auditory profile and cadence of that speech mode. The results are applied to the full corpus to obtain "naïve" estimates of each utterance's tone, based only on the audio features and ignoring conversational context. We then fit a model for the flow of conversation, use this to refine the "contextualized" tone estimates, and repeat in an iterative procedure. The specifics of each step are discussed below and in Online Appendix Section 1, and the workflow is outlined more formally in Algorithm 1.

Table 1 summarizes the data available for the primary corpus and training set, respectively indicated with $\mathcal{C}$ and $\mathcal{T}$. The audio characteristics of each utterance, $\boldsymbol{X}$, are observed for both the primary corpus and the training set. However, human-labeled tone of speech, $S$, is only known for the training set. We divide the conversational context into externally given but potentially time-varying "static metadata," $\boldsymbol{W}^{\text {stat. }}$, and deterministic functions of conversational history that dynamically capture the prior tones of speech, $W^{\text {dyn. }}$. The former is known for the primary corpus but may be unavailable for the training set, depending on how it is constructed; the latter is not directly observed for either.

Our ultimate goal is to estimate the conversational flow parameters, $\zeta$, and the auditory parameters of each tone, which we gather in $\Theta^{m}=\left(\mu^{m}, \Sigma^{m}, \Gamma^{m}\right)$ for compactness. In what follows, we also refer to the collection of all tone parameters as $\Theta=\left(\Theta^{m}\right)_{m \in\{1, \ldots, M\}}$. Under the model described in Equations 1-2, the likelihood can be expressed as

$$
\begin{aligned}
& \mathscr{L}\left(\zeta, \Theta \mid \boldsymbol{X}^{\mathcal{T}}, \boldsymbol{S}^{\mathcal{T}}, \boldsymbol{X}^{\mathcal{C}}, \boldsymbol{W}^{\text {stat., } \mathcal{C}}\right) \\
& \quad=f\left(\boldsymbol{X}^{\mathcal{C}} \mid \zeta, \Theta, \boldsymbol{W}^{\text {stat., }}\right) f\left(\boldsymbol{X}^{\mathcal{T}} \mid \Theta, \boldsymbol{S}^{\mathcal{T}}\right),
\end{aligned}
$$

with one factor depending only on the primary corpus and another containing only the training set.

As a concession to computational constraints, we estimate the parameters in a stagewise fashion. The auditory parameters, $\Theta$, are calculated by maximizing the partial likelihood, $f\left(\boldsymbol{X}^{\mathcal{T}} \mid \Theta, S^{\mathcal{T}}\right)$, corresponding to the training factor, rather than the full likelihood in Equation 5 (Wong 1986). The full likelihood is then maximized with respect to the conversational flow parameters $\zeta$, conditional on $\Theta$. The factorization and a detailed discussion of stagewise estimation are presented in Online Appendix Section 1.1.

In Online Appendix Section 1.2, we detail our procedure for estimating the auditory profile and cadence for each speech mode. First, training utterances are divided according to their tone labels. Because the partial likelihood can be neatly factorized further as $f\left(\mathbf{X}^{\mathcal{T}} \mid \Theta, \boldsymbol{S}^{\mathcal{T}}\right)=\prod_{m=1}^{M} \prod_{u \in \mathcal{T}} f\left(\boldsymbol{X}_{u} \mid \Theta^{m}\right)^{\mathbf{1}\left(S_{u}=m\right)}, \widehat{\Theta}^{m}$ can be independently estimated for each speech mode with no further loss of information. For all training utterances of speech mode $m$, a regularized variant of the Baum-Welch algorithm, a standard estimation procedure for hidden Markov models, is used to obtain $\widehat{\Theta}^{m}$ for the corresponding mode. Each of the resulting $M$ tonespecific models are then applied to each utterance $u$ in the primary corpus to obtain the corrected emission probabilities $f\left(\boldsymbol{x}_{u} \mid \widehat{\Theta}^{m}, S_{u}=m\right)^{\rho}$, which represents the probability that the utterance's audio was generated by speech mode $m$; this captures the extent to which the audio "sounds like" the relevant training examples. Naïve tone estimates can then be computed by combining these with the overall prevalence of each tone via Bayes' rule. The corrective factor, $\rho$, approximately accounts for unmodeled autocorrelation in the audio features and ensures that the naïve estimates are well calibrated (for details, see Online Appendix Section 1.3). This shared correction, along with the number of latent sounds and strength of regularization, are determined by likelihood-based cross validation (van der Laan, Dudoit, and Keles 2004) in the training set. 
We now briefly describe an expectationmaximization algorithm for the conversation-flow parameters, $\zeta$, reserving derivations and other details for Online Appendix Section 1.4. ${ }^{8}$ An inspection of Equation 5 shows that this procedure will depend only on $f\left(\boldsymbol{X}^{\mathcal{C}} \mid \zeta, \Theta, \boldsymbol{W}^{\text {stat., } c}\right)$, since the remaining term does not involve $\zeta$. We proceed by augmenting the observed data with the latent tones, $S^{\mathcal{C}}$, and the conversation-history variables that depend on them, $W^{\text {dyn., }}$. The augmented likelihood, $f\left(\boldsymbol{X}^{\mathcal{C}}, \boldsymbol{S}^{\mathcal{C}}, \boldsymbol{W}^{\text {dyn., } \mathcal{C}} \mid \zeta, \Theta, \boldsymbol{W}^{\text {stat., } \mathcal{C}}\right)$, is then iteratively optimized. However, the closed-form expectation of the augmented likelihood is intractable. We therefore replace the full E-step with a blockwise procedure that sweeps through the unobserved E-step variables sequentially. ${ }^{9}$ Finally, the maximization step for $\zeta$ reduces to a weighted multinomial logistic regression in which $\mathbf{1}\left(S_{u}=m\right)$ is fit on $\mathbb{E}\left[\boldsymbol{W}_{u} \mid S_{u-1}=m^{\prime}\right]$ for every possible $m$ and $m^{\prime}$, with weights corresponding to the probability of that transition.

Finally, we observe that the unmodeled autocorrelation discussed above renders model-based inference invalid. To address this issue, we estimate the variance of parameter estimates by bootstrapping utterances in the training set, ensuring that dependence between successive moments in an utterance do not undermine our results (Online Appendix Section 1.5 discusses potential issues in bootstrapping). The full estimation procedure is outlined in Algorithm 1. Other quantities of interest, such as those discussed in "Testing Theories of Supreme Court Deliberation," follow directly from the conversation-flow parameters, $\zeta$, or the auditory parameters, $\Theta$; inference on these quantities follows a similar bootstrap approach.

\section{A NEW QUANTITY OF INTEREST IN JUDICIAL BEHAVIOR}

In this section, we introduce an original corpus of Supreme Court oral argument audio recordings scraped from the Oyez Project (Cornell 2015) ${ }^{10}$ and develop a new quantity of theoretical interest: judicial skepticism. We first describe the data, then illustrate the concept of skepticism with a detailed case study. Finally, we extensively validate the model and compare it with related work analyzing the text of oral arguments alone. Importantly, we demonstrate that this substantive quantity is not measurable with existing methods. Text-based classifiers are on par with random guessing

\footnotetext{
${ }^{8}$ This estimation procedure builds on forward-backward algorithms; interested readers are referred to Online Appendix Section 1.2 or standard references such as Zucchini and MacDonald (2009).

${ }^{9}$ The use of this alternative procedure leads to a smaller improvement of the EM objective function than a full E-step. Nevertheless, algorithms using such partial E- or M-steps ultimately converge to a local maximum, just as traditional expectation-maximization procedures do (Neal and Hinton, 1998).

${ }^{10}$ Dietrich, Enos, and Sen (2019) independently collected the same audio data and conducted an analysis of vocal pitch.
}

Data: Audio features $\left(\boldsymbol{X}^{\mathcal{C}}, \boldsymbol{X}^{\mathcal{T}}\right)$, static metadata for primary corpus $\left(W^{\text {stat., } \mathcal{C}}\right)$

Result: Auditory parameters $\Theta$, conversational flow parameters $\zeta$

\section{Procedure:}

\section{Define problem}

Analyst determines tones of interest and rubric for human coding. Human-coded tone labels are obtained for training set $\left(S^{\mathcal{T}}\right)$.

2. Fit auditory parameters $(\Theta)$ by maximizing partial likelihood on training set $(\mathcal{T})$.

for speech mode $m$ in $1, \ldots, M$ do

Subset to training utterances labeled as tone $m$.

while not converged do

for utterance $u$ in $\mathcal{T}$ and moment $t$ in $\left\{1, \ldots, T_{u}\right\}$ do for sound $k$ in $1, \ldots, K$ do Compute emission probability of sound $(m, k)$ generating audio $\left(\boldsymbol{X}_{u, t}\right)$. end

end

Predict sound being pronounced at each moment $\left(R_{u, t}\right)$. Update cadence (usage patterns of constituent sounds, $\Gamma^{m}$ ). for sound $k$ in $1, \ldots, K$ do | Update audio profile of sound $k\left(\boldsymbol{\mu}^{m, k}, \boldsymbol{\Sigma}^{m, k}\right)$. end end

end

\section{Fit conversational flow parameters $(\zeta)$ using primary corpus} $(\mathcal{C})$, conditional on $\Theta$.

for utterance $u$ in $\mathcal{C}$ do

for speech mode $m$ in $1, \ldots, M$ do Compute corrected emission probability of speech mode $m$ generating utterance audio data $\left(\boldsymbol{X}_{u}\right)$, ignoring context. end

end

while not converged do

Predict expected mode of speech for each utterance $\left(S_{u}\right)$

Compute expected conversation context for each utterance $\left(\boldsymbol{W}_{u}\right)$. Update flow-of-speech parameters $(\boldsymbol{\zeta})$. end

Algorithm 1: Stagewise Estimation Procedure. After defining the tones of interest and obtaining a labeled training set, the analyst conducts cross validation to set ancillary parameters such as the number of assumed sounds in each mode of speech (not depicted). After fixing the ancillary parameters, the cadence and auditory characteristics of each speech mode are estimated from the training set by an iterative expectationmaximization procedure. These speech parameters are then fixed, and the relationship between conversational context and flow of speech is estimated from the primary corpus. In the multiple-conversation case, the utterance loop in step 3 is nested within an outer loop over conversations. Statistical inference is conducted by resampling $\mathcal{T}$ and repeating steps $2-3$ within the bootstrapped training set (not depicted) to obtain bootstrap-aggregated point estimates and bootstrap variance estimates for flow-of-speech parameters and other quantities of interest.

(or worse, depending on the evaluation metric), whereas MASS performs nearly as well as human coders. A full analysis of deliberation in oral arguments - a theoretical analysis that is possible only with 
a model for speech flow-is reserved for "Testing Theories of Supreme Court Deliberation."

\section{Audio Data from Supreme Court Oral Arguments}

We limit our analysis to the natural court that begins with the appointment of Justice Kagan and concludes with the passing of Justice Scalia, so that the composition of the Court remains constant for the entirety of the period we analyze. The Oyez data contains an accompanying textual transcript, speaker names for each utterance, and timestamps for utterance start and stop times. In addition, we inferred the target side (i.e., petitioner or respondent) of each justice's question based on the side of the most recently speaking lawyer. Additional case data were merged from the Supreme Court Database (Spaeth et al. 2014).

Using Oyez timestamps, we segmented the fullargument audio into a series of single-speaker utterances. ${ }^{11}$ As an additional preprocessing step, we drop utterances spoken by lawyers (each of whom usually appears in only a handful of cases) and Clarence Thomas (who spoke only twice in our corpus), focusing on the behavior of the eight recurrent speakers. We also drop procedural statements, along with utterances shorter than 2.5 seconds. ${ }^{12}$ After trimming and dropping cases in which the ideological direction is unclear, the resulting audio corpus contains 266 arguments and 95 hours of audio, comprising nearly 42,000 utterances and over 27 million frames.

\section{The Quantity of Interest: Judicial Skepticism}

In this section and the next, we introduce and employ a new measure of substantive importance to the study of courts: judicial skepticism, an individual's vocal expression of their judgment about the argument at hand. Judicial skepticism is an important signal of disagreement with or incredulity about assertions and legal arguments, especially in the context of oral arguments.

To identify judicial skepticism in speech, we first randomly selected a training set of 200 utterances per justice to hand-classify as "skeptical" or "neutral" speech, allowing our assessments to reflect not only the vocal tone but also the textual content of the

\footnotetext{
${ }^{11}$ Occasionally, segments are reported to have negative duration, due to errors in the original timestamps. In these cases, we drop the full "turn," or uninterrupted sequence of consecutive utterances by this speaker.

${ }^{12}$ We found that these extremely short utterances contained substantial amounts of crosstalk. However, they also include potentially informative interjections; future work may explore improved preprocessing techniques that do not require discarding this information. ${ }^{13}$ Because the transcripts attribute each utterance to a speaker, the model's decision is over whether the current statement by Anthony Kennedy was skeptical or neutral. That is, we do not conduct a joint speaker-recognition and tone-detection task. In the framework outlined in Equations 1-2, this is equivalent to introducing a covariate for the current speaker's identity, with a corresponding coefficient of $-\infty$ for the 14 speech modes that do not correspond to the current speaker.
}

utterance. Thus, we define 16 modes of speech-two tones for each of the eight speaking justices. ${ }^{13}$ During classification, we dropped the handful of utterances (roughly $5 \%$ ) in which crosstalk or other audio anomalies occurred or in rare instances where the speaker's identity was incorrectly recorded. The model is then estimated following Algorithm 1.

\section{A Case Study of Judicial Skepticism}

To illustrate the use of skepticism during the flow of oral arguments, we conducted a case study of Alabama Legislative Black Caucus v. Alabama, a racial gerrymandering case heard by the Supreme Court in 2014 that considered the legality of Alabama's 2012 redistricting efforts. The study is described in depth in Online Appendix Section 3; we briefly summarize it here and demonstrate the application of MASS to this case in Figure 3.

As background, the case arose when the Republicanled legislature redrew electoral districts in the face of declining urban population. In doing so, the legislature sought to pack Black voters into a small number of already heavily Democratic districts. The liberal Alabama Legislative Black Caucus argued that this practice violated the Voting Rights Act (VRA), a position ultimately supported by the Court's decision, whereas conservative defenders of the new map argued that Section 5 of the VRA in fact forced the legislature to draw Black-dominated districts.

Figure 3 depicts two exchanges in which justices spar over this legal claim about Section 5-that a state must hold or increase the numerical percentage of Black voters in a district to maintain minorities' "ability to elect their preferred candidates." In the first exchange, beginning with Justice Scalia's question, "Well, $I$ thought the Section 5 obligation ...," Justice Scalia advocates the conservative view when questioning the liberal advocate. Median Justice Kennedy, perhaps influenced by this line of questioning, pursues it further and transitions into skepticism on the technical point of whether the liberal reading of the VRA constitutes an indefensible "oneway ratchet" on minority percentages. Justice Breyer then comes to the defense of the liberal side, asking the friendly rhetorical question-ostensibly to the advocate-of whether Justice Kennedy's question was addressed by precedent. Later in the oral argument, these roles reverse. The figure depicts a subsequent exchange in which Justice Kennedy initiates a line of questioning, Justice Breyer attacks by skeptically saying to the conservative advocate, "I don't know what the defense is possibly going to be," and Justice Scalia comes to the rescue with a "softball" question.

These exchanges illustrate the sort of political interactions modeled by MASS. Panel 3.A depicts how skeptical and neutral speech are deployed throughout the discussion, and Panels 3.B.1-3 each highlight a justice's choice of tone (e.g., the decision to switch from neutrality to skepticism, which we model using covariates such as conversational history or the ideology of the side currently being questioned). Panels 3.C.1-2 examine two utterances in depth, showing a subset of the auditory features that MASS relies on to infer 


\section{FIGURE 3. An Illustrative Example}
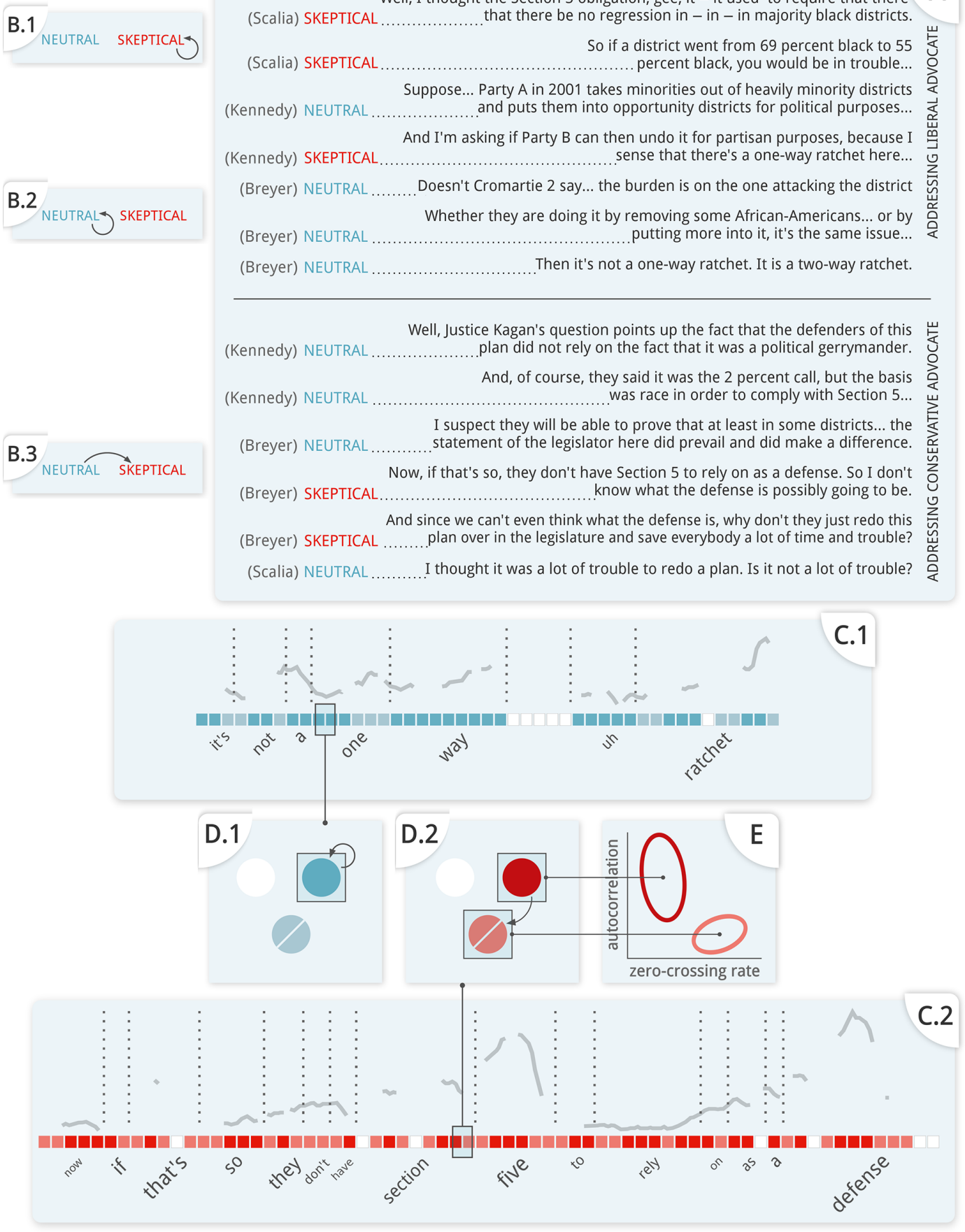

Note: Panel A contains excerpts from Alabama Legislative Black Caucus v. Alabama, where Justices Scalia, Kennedy, and Breyer utilize neutral and skeptical tones in questioning. Call-outs highlight successive utterance pairs in which the speaker shifted from one mode to another (B.3), and continued in the same tone of voice (B.1 and B.2). Panels C.1 and C.2 illustrate the use of loudness (text size) and pitch (contours) within utterances: in the neutral mode of speech (C.1), speech varies less in pitch and loudness when compared with skeptical speech (C.2). Based on these and other features, MASS learns to categorize sounds into vowels (dark squares), consonants (light), and pauses (white). Call-outs D.1 and D.2 respectively identify sequential moments in which a "neutral" vowel is sustained (transition from the dark blue sound back to itself, indicating repeat) and the dark red "skeptical" vowel transitions to the light red consonant. Panel E shows the differing auditory characteristics of the "skeptical" vowel and consonant, which are perceived by the listener. 
speech tone. Each tone is modeled as a sequence of discrete sounds, like "vowel" or "silence"; their usage is shown in Panels 3.D.1-2, and their auditory content is in Panel 3.E.

\section{Validating the Model}

We conduct extensive validation of our model-based measure of judicial skepticism, confirming that MASS does in fact successfully estimate the quantity of interest. Due to space constraints, we summarize these efforts here; results are described in detail in Online Appendix Section 4.

First, we demonstrate that MASS recovers a measure that has high face validity. Online Appendix 4.1 presents randomly sampled utterances from the highest and lowest deciles of model-predicted skepticism. Those characterized by the model as skeptical include gentle mockery and doubtful questions, whereas modelpredicted neutral utterances are factual statements and straightforward legal analysis.

Second, we examine content validity in Online Appendices 4.2-4.3. Our model detects skepticism based on linguistically and physiologically meaningful auditory features. In a model of Justice Kennedy's expressed skepticism, compared with neutral questioning, we find that his speech is louder, contains more pitch variation, and is characterized by higher vocal tension. We caution that MASS does not take textual signals of skepticism into account, an important limitation on content validity. (Joint models of audio and text remain an important direction for future work.) However, we demonstrate that in the case of judicial speech, there are extremely few textual signals that distinguish skepticism from typical questioning.

Third, in Online Appendix 4.4, we estimate a lower bound on the out-of-sample performance of MASS, using cross-validation results from the lower stage of the model, corresponding to Equations 3-4 and excluding Equations 1-2. We find that out-of-sample accuracy of the lower-level auditory classifier is $68 \%$, versus the $52 \%$ that would be obtained by randomly permuting labels; numerous additional performance metrics are reported in the appendix. ${ }^{14}$

Fourth, we compare the performance of MASS with (1) human coders and (2) text-based classifiers. For the human comparison, we recruited native English speakers on a crowdworking site and evaluated their ability to recover ground-truth labels in legal argumentation. We found that when combining responses by majority vote, nonexpert listeners were able to detect $70 \%$ of judicial skepticism, outperforming MASS by a small margin. The performance of individual coders was lower, at $65 \%$, suggesting that with a relatively small amount of domain-specific data, our model performs approximately as well as humans with a lifetime of experience in parsing non-domain-specific speech. For the textual comparison,

\footnotetext{
${ }^{14}$ Performance varies considerably depending on the auditory label of interest. As the comparison with nonexpert human coders shows, detecting judicial skepticism is a particularly difficult task.
}

we applied an elastic net to utterance word counts. The resulting trained text models were entirely degenerate, predicting the more common label in virtually every case.

Finally, we probe the predictive validity of our measure with a comparison to Black et al. (2011), described in the next section.

\section{Comparison with an Existing Measure}

We conduct yet another validity test by contrasting our model with the approach of Black et al. (2011), who use a measure based on directed pleasant and unpleasant words-operationalized with the Dictionary of Affect in Language (DAL; Whissell 2009) - to predict justice voting. We replicate and contrast results with those from a comparable measure of directed skepticism. ${ }^{15}$ Specifics are discussed in Online Appendix 4.5. We find that a one-standard-deviation increase in directed unpleasant (pleasant) words is associated with a 2.8-percentage-point decrease (no difference) in the probability that a justice votes against a side. In comparison, a one-standard-deviation increase in directed skepticism, as estimated from auditory characteristics, is associated with a 7.9-percentage-point decrease in vote probability-nearly three times as large. Moreover, Figure 4 shows that unlike text-based results, these patterns are robust to the inclusion of both justice and case fixed effects.

Why is speech tone so much more predictive of voting patterns than the use of affective words? One reason may be that DAL uses a cross-domain measure of word pleasantness, ignoring the fact that words often take on different meanings in legal contexts. For example, the the 10 most common "unpleasant" words in our corpus include "argument" and "trial," whereas the five most common "pleasant" words include "read" and "justice." However, as we show in other text-audio comparisons, a more likely explanation is that word choice is a noisy, high-dimensional, and difficult-tomeasure signal of expressed emotion, whereas auditory tone is relatively structured and consistent.

However, we note that MASS exploits only the auditory channel of speech. While we show in Online Appendix 4.4 that this provides a clearer signal of skepticism than text in general, there are nonetheless cases when expressions of disbelief are spoken flatly. In one example, Justice Ginsburg states matter-of-factly, "Well, that would be fine if the statute said what you claim it said." The utterance is clearly skeptical, yet our model predicts that it is $89 \%$ likely to be neutral speech due to its deadpan delivery. This counterexample highlights limitations in the use of any communication channel in isolation, suggesting that joint models of text and tone are a necessary direction for future work.

Next, we demonstrate the model with an application to speech in Supreme Court oral arguments, then conclude.

\footnotetext{
${ }^{15}$ Our measure of directed skepticism is based on lower-level HMMs alone, since the complete model incorporates voting as a covariate.
} 


\section{FIGURE 4. Predicting Justice Votes with Directed Skepticism and Directed Affective Language}

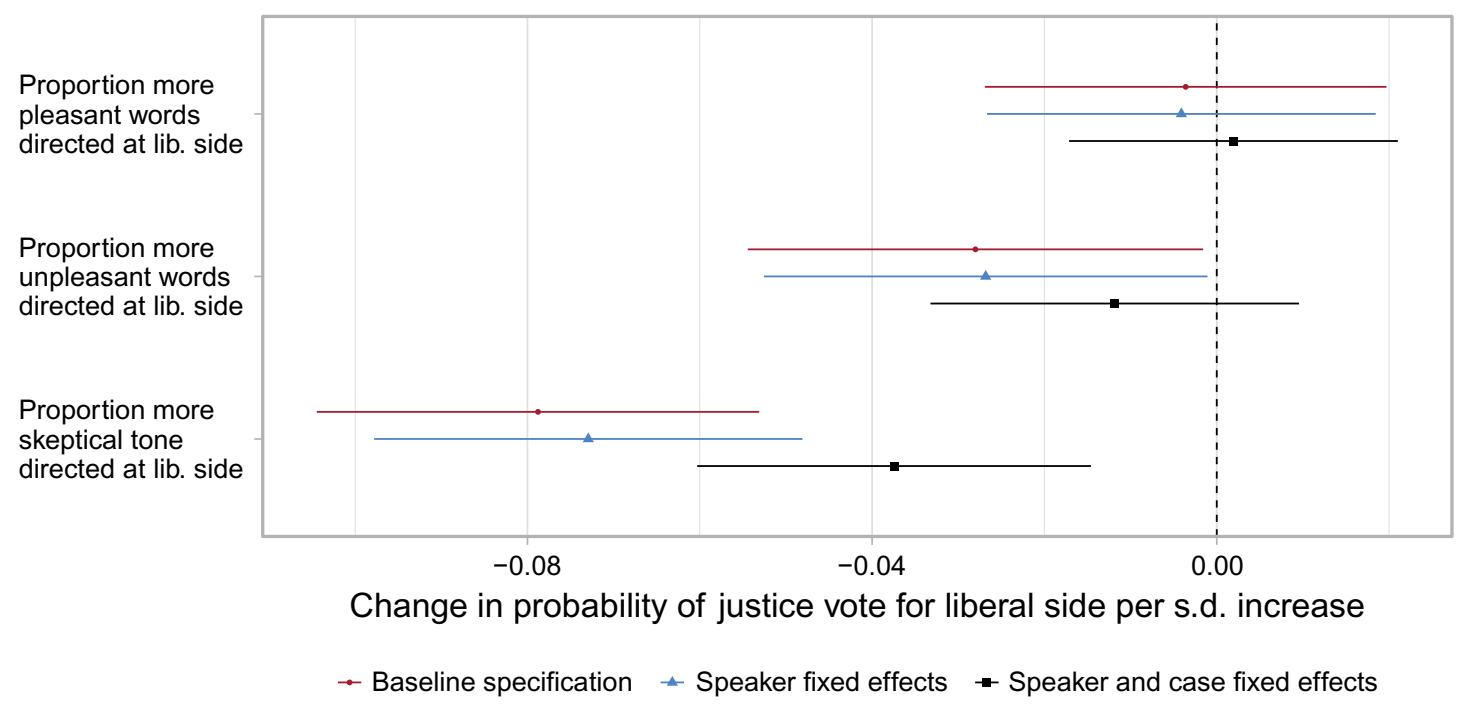

Note: Horizontal error bars represent point estimates and 95\% confidence intervals from regressions of justice votes on directed pleasant words, directed unpleasant words, and our audio-based directed skepticism. Red circles correspond to a specification with no additional controls; blue triangles report results with speaker fixed effects only, black squares with speaker and case fixed effects.

\section{TESTING THEORIES OF SUPREME COURT DELIBERATION}

While some scholars believe that oral arguments are inconsequential in Supreme Court decision-making (Rohde and Spaeth 1976; Segal and Spaeth 1993), others argue that they play a crucial role in shaping the Court's ultimate position on a case (Black, Sorenson, and Johnson 2013; Epstein, Landes, and Posner 2010; Johnson 2001; Johnson, Wahlbeck, and Spriggs 2006; McGuire 1995; Shapiro 1984; Wasby, D’Amato, and Metrailer 1976). The justices themselves, however, are virtually unanimous on this point. Justice Powell stated, "The fact is, as every judge knows ... the oral argument ... does contribute significantly to the development of precedents" (Stern, Gressman, and Shapiro 1993, 571). Johnson and Goldman (2009) document numerous other direct quotes about the importance of oral arguments, including Justices Harlan, Hughes, Jackson, Brennan, White, Rehnquist, and others.

But there is little empirical evidence about how arguments matter. Courts scholars have advanced various accounts of the deliberative process, which can be roughly grouped into two broad theories. For concreteness, we discuss these theories and their associated mechanisms in the context of Rapanos v. United States, a narrowly decided environmental case about the Army Corps of Engineers' right to regulate pollution in wetlands, drawing extensively on legal analysis by Savage (2009). ${ }^{16}$

The first theory holds that justices are shrewd political actors who maneuver to influence the decisions of their peers in pursuit of a desired case outcome

\footnotetext{
${ }^{16}$ The full argument is available at https://www.oyez.org/ cases/2005/04-1034.
}

(Epstein, Landes, and Posner 2010, 2013; Iaryczower and Shum 2012; Iaryczower, Shi, and Shum 2018; Shullman 2004). In this account, oral arguments represent an opportunity for justices to strategically signal to their colleagues, with lawyers and their legal arguments serving merely as convenient foils. Justice Breyer $(1998,56)$ says as much, noting, "We're always trying to persuade each other. But persuading each other is complicated... [one way] is to identify what you think of as the difficult problem in a case, and then pose a question that will reveal the difficulty in some way." Justice Sotomayor (2019) concurs, saying "sometimes we're talking to each other, and we're raising points through the questions that we want our colleagues to consider with us." These attempts at persuasion appear to be on display in Rapanos v. United States. From the very start of arguments, battle lines were drawn over the precise definition of a "watershed," which determined the Corps' jurisdiction. Justice Roberts, a well-known opponent of what he views as the agency's regulatory overreach, sought to undermine its position: "To $m e$ it ... it suggests that even the Corps recognized that at some point you've got to say stop, because logically any drop of water anywhere is going to have some sort of connection through drainage."

Conversely, the liberal wing of the court attacked the Pacific Legal Foundation's (PLF, a conservative property-rights advocacy group) position that the federal government should not have jurisdiction over local pollution unless it can prove that a polluter's waste reached a navigable waterway. Justice Souter-whose support for greater environmental protection was previously made clear in SWANCC v. United Statesridicules this position, asking, "You mean... in every case, then ... a scientist would have to analyze the molecules and ... trace it to a specific discharge?" 
On its face, it seems plausible that these justices sought to sway Justice Kennedy on this pivotal issue. The point was of critical importance to Justice Kennedy, more so than any other justice. ${ }^{17}$

But were those questions intentionally deployed to shape the subsequent flow of conversation - and ultimately, voting? Or would Justices Roberts and Souter have taken the same stance even if the outcome of the case were not in question? A second, largely incompatible conception of the decision-making process considers justices as neutral arbiters, each casting a sincere vote according to rules determined by their respective legal philosophies (Black et al. 2011; Black, Schutte, and Johnson 2013; Johnson 2001). In this latter account, oral arguments primarily operate as opportunities for fact-finding, rather than persuasion. Justice Douglas summarized this position best, stating, "The purpose of a hearing is that the Court may learn what it does not know" (Galloway 1989). Justice Thomas (2013) famously goes a step further, saying, "I think it's unnecessary to deciding cases to ask that many questions, and I don't think it's helpful." And while justices may reveal their predispositions with a display of doubt, this theory suggests that it is merely an honest response to compelling or uncompelling legal reasoning, rather than an effort to manipulate. For example, Justice Scalia was unable to contain his skepticism after Justice Souter's attack, exclaiming, "Well, I . . couldn't you simply assume that anything that is discharged into a tributary, ultimately, goes where the tributary goes? ... You really think it has to trace the molecules?" His outburst, which undermined the position of the PLF (his preferred side), suggested a genuine response to a difficult-to-believe position rather than an attempt at persuasion.

These competing accounts are challenging to disentangle even under the best of circumstances. This difficulty has been compounded by widespread reliance on a narrowly limited representation of judicial speech: textual transcripts alone. Here, we demonstrate that the discarded audio channel contains information of enormous value to social scientists - and that by modeling the tone it conveys, MASS not only opens the door to new research questions but can also shed new light on existing puzzles. Specifically, we use MASS to analyze the structural determinants of expressed skepticism in oral arguments. Using justices' ideological leanings, their ultimate vote, and a measure of case contentiousness, we test the observable implications of two commonly espoused but conflicting narratives of the Supreme Court decision-making process: that justices are highly strategic actors jockeying for influence, on one hand (Black, Schutte, and Johnson 2013), or alternatively that they are neutral arbiters

\footnotetext{
${ }^{17}$ At one point, he clarifies, "I think what the Court is asking you ... is how to define 'significant nexus,"” to a navigable waterway. This point of contention is mentioned 29 times in Kennedy's separate concurrence-compared with 31 times in the opinion, Roberts' concurrence, and both dissents combined. Moreover, 19 of these mentions were in reference to Kennedy's position.
}

who respond genuinely to compelling legal arguments (Johnson, Wahlbeck, and Spriggs 2006).

Differing theoretical accounts of deliberation suggest very different patterns in the usage of this tone. A model of genuine voting implies that when justices communicate their skepticism (to the extent that they make it known at all), it is largely as a natural reaction to poor argumentation. In other words, we should observe generically higher rates of skepticism when justices question lawyers for the side that they find less persuasive. This leads to an observable implication of the genuine-voting theoretical account: when a justice votes against a side, we should observe that this behavior is associated with increased skeptical questioning of the corresponding lawyers (Black et al. 2011; Black, Sorenson, and Johnson 2013).

A strategic-signaling model of deliberation, on the other hand, must account for the fact that manyindeed, nearly half - of all cases are decided unanimously. When all justices agree, no strategy is necessary. There is little to gain from posturing, including acted skepticism. To the extent that experienced justices are able to identify uncontroversial cases from preargument legal briefs and lower court decisions, this suggests a key observable implication of the strategicsignaling account: justices should exhibit greater skepticism toward their non-preferred side, especially in contentious cases. That is, in cases that are ultimately decided by a 5-4 margin, we should see justices use markedly more skepticism toward the side they vote against. Forward-looking justices should similarly reduce skepticism toward their own side to avoid damaging its chances in close calls. ${ }^{18}$ To further adjudicate between these competing explanations, we turn to a dynamic test of oral arguments, in which the implications of each theory are even cleaner.

In general, justices who are ideologically close will exhibit greater similarity in preferences and judicial perspectives relative to those who are far apart. When justice $i$ finds a line of legal reasoning to be objectionable (as manifested in an expression of skepticism), it is likely that their ideological neighbor $j$ will find it objectionable as well. The two narratives then diverge in their predictions for $j$ 's response. A genuine reaction would be to acknowledge the flaw in reasoning, perhaps following up with further skeptical probing regardless of $j$ 's affinity for the lawyer under attack. In contrast, if $i$ is ideologically distant from $j$, then $i$ 's skepticism should not provoke much of a response from $j$ due to the relative lack of shared views on hot-button issues. The strategic account, on the other hand, implies a very different flow of questioning. Suppose that $j$ opposes the current lawyer. If $j$ were a savvy justice, they should be on the lookout for weaknesses in the opposing side's arguments, seizing the chance to

\footnotetext{
${ }^{18}$ We note that persuading justices to change their vote is not the only potential incentive in a strategic model of judicial questioning. For instance, justices may wish to shift the opinion's content even when expecting a unanimous decision, though this does not undermine the general logic of our test.
} 
dogpile when an opportunity presents itself. Ideological distance from $i$-the preceding critic-should not restrain the shrewd operator much, if at all. (Indeed, a left-right combination may be a particularly effective blow against the current lawyer.)

The strategic narrative suggests a very different sequence of events when $j$ 's preferred side comes under attack, however. When ideological neighbor $i$ expresses skepticism, $j$ has an incentive to smooth things overdespite $j$ 's ideological inclination to agree with $i$ 's points. Thus, the extent to which ideological proximity colors $j$ 's response to prior skepticism is a useful point of differentiation. Specifically, we discretize ideology into "left" (Justices Breyer, Ginsburg, Kagan, and Sotomayor) and "right" (Justices Alito, Roberts, and Scalia), setting Kennedy aside, given his unique position at the median. We then test whether a justice agrees with their usual allies - that is, expresses skepticism togethereven when that skepticism is directed against their preferred side. If so, this suggests a genuine response; if not, it suggests that justices may be strategically pulling their punches to protect case-specific interests.

The observable implications described above utilize post-argument proxies for justice preferences (vote) and case divisiveness (margin of victory). A natural concern is that a justice's ultimate vote may be influenced by the course of questioning as well. In this case, persuasion may offer an alternative explanation for patterns in observed skepticism. If strategic justices are always successful in persuading their colleagues, the genuine-voting and strategic-signaling accounts become observationally similar in many cases. While we find this level of persuasiveness to be implausible in light of extensive qualitative work on the courts (Ringsmuth, Bryan, and Johnson 2013; Wolfson 2001), there is considerable room for future work to improve on our analysis. These improvements may include more rigorous formal modeling of strategic interaction in the deliberative process, collection of better pre-argument proxies for justice predisposition and case controversiality (e.g., circuit court votes; see also Online Appendix Section 4.6, which suggests that ideologically directed skepticism may reveal intensity of preferences by issue area), or analysis of natural experiments (e.g., exploiting justice retirements).

Finally, note that in interpreting model parameters and testing theories, we formulate all hypotheses in the following manner: Conditional on justice $i$ speaking, is it more likely that they do so skeptically in one conversational context, as opposed to another? ${ }^{19}$ The competing narratives described above suggest several observable implications for the structural determinants of justice tone-for example, how the side currently being questioned or the tone of the previous questioner translates into expressed skepticism.

Figure 5 presents results from two MASS specifications. First, we model transition probabilities (i.e., the

\footnotetext{
${ }^{19}$ This formulation allows us to parcel out any shifts in speaker frequencies, which besides being difficult to theorize are also relatively uninteresting.
}

probability that the next utterance is of justice-tone $m$ ) as $\exp \left(\boldsymbol{W}_{u}^{T} \zeta_{m}\right) / \sum_{m^{\prime}=1}^{M} \exp \left(\boldsymbol{W}_{u}^{T} \zeta_{m^{\prime}}\right)$, where the conversational context $W$ includes the eventual case margin, the ultimate vote of the justice in question, an interaction, and a justice-tone intercept. We then average across justices according to their speech frequency to obtain an average effect. The results show that justices use skepticism against their nonpreferred side-either the petitioner or respondent, depending on whom they go on to vote against - at a significantly higher rate, as expected.

Contrary to theoretical predictions under strategic signaling, however, we find no indication that the gap between petitioner- and respondent-targeted skepticism depends on the margin of the case decision. That is, the difference in differences is far from significant. We do find that skepticism is generically higher across the board in close cases. These results are consistent with the account that Supreme Court justices are engaged in genuine fact finding, not a strategic attempt to manipulate their colleagues, and that they particularly seek to get answers right when the stakes are high. ${ }^{20}$

To probe further, we now turn to the dynamics of argumentation. In an expanded specification, we now incorporate additional binary indicators for whether the preceding speaker belonged to the liberal or conservative wing of the Court, as well as interactions between skepticism in the preceding utterance, ideology of the previous speaker, and vote. As described above, the strategic model of judicial signaling implies that after a peer-any peer-criticizes a justice's preferred side, the justice should withhold comment or defuse tensions with neutral commentary. By the same token, the savvy justice should follow up with a coup de grâce after a colleague finds fault in the disfavored side's reasoning. We find no evidence that this is true. Rather, our results are highly consistent with a model of genuine expression in which justices concede to the criticisms of ideologically proximate peers, regardless of their case-specific interests. That is, after a liberal (conservative) justice casts doubt on a lawyer's argument, other liberals (conservatives) on the Court are likely to follow suit even if that criticism undermines their favored side.

\section{CONCLUDING REMARKS}

In the last decade, computational social science made tremendous advances in the automated analysis of what speakers say. However, analysis of how those words were spoken has largely eluded principled inquiry. MASS addresses this limitation by providing a framework for statistical analysis of the nontextual components of speech. And by directly modeling patterns in communication, MASS allows analysts to address a host of elusive questions about its structure and temporal dynamics.

\footnotetext{
${ }^{20}$ As we note in detail above, we cannot entirely rule out the alternative explanation that some of these results are due to persuasion over the course of oral arguments.
} 
FIGURE 5. Simulated Quantities of Interest
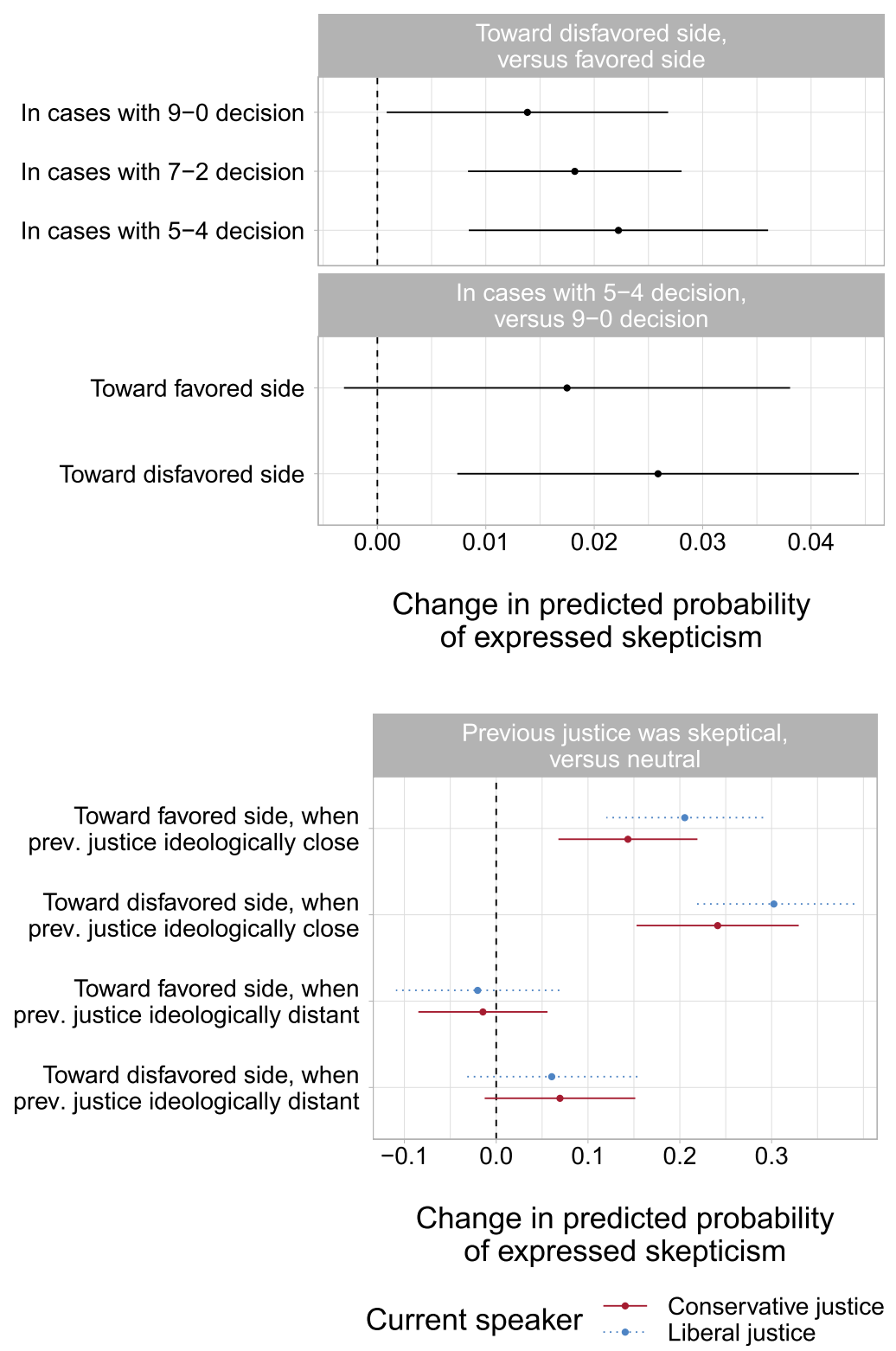

Note: Each panel manipulates a single variable from a control value (second element of panel title) to a treatment value (first). Points (error bars) represent changes ( $95 \%$ bootstrap confidence intervals) in predicted skepticism. We average over all other nuisance covariates (e.g., the identity of the next speaker) of the scenario-specific change in outcome, weighting by the empirical frequencies of these covariates. The top panel shows that justices deploy skepticism more often toward their nonpreferred side. The second panel compares close votes with unanimous decisions, demonstrating that justices express more skepticism across the board in the former. However, justices do not attempt to target a particular side in close votes; rather, they simply ask more skeptical questions across the board. Finally, the bottom panel shows that justices mirror the tones of their ideological neighbors, who share similar legal philosophies, even when those neighbors are opposed to the justice's case-specific voting interests.

Our analysis demonstrates the importance of these patterns - speech flow - not only in audio data but also in the analysis of speech more broadly. While structural models of text that incorporate metadata are now in widespread use (Roberts et al. 2014), temporal dynamics have received far less attention. Yet speech-and especially conversation-is obviously temporally dependent. We consider MASS not as the final word on speech analysis but rather as a step toward statistical models that more fully capture the complex data- generating process that gives rise to all elements of human speech.

This effort to respect the data-generating process underlies many of the design decisions in our model. For example, in representing speech with many time-varying features, MASS makes an enormous improvement over existing approaches that collapse communication down to simplistic summary statistics, such as average pitch. However, this extension is not without trade-offs, particularly in computational 
complexity and the need for human expertise. The distinction may be analogous to that between sophisticated context- and semantics-aware text classifiers and straightforward dictionary-based methods that count word occurrences. The advantages of each are worth explicit consideration in future research.

\section{SUPPLEMENTARY MATERIALS}

To view supplementary material for this article, please visit http://dx.doi.org/10.1017/S000305542000101X.

Replication materials can be found on Dataverse at: https://doi.org/10.7910/DVN/8BTOHQ.

\section{REFERENCES}

Anderson, Rindy, and Casey Klofstad. 2012. "Preference for Leaders with Masculine Voices Holds in the Case of Feminine Leadership Roles." PloS One 7 (12): e51216.

Anderson, Rindy, Casey Klofstad, William Mayew, and Mohan Venkatachalam. 2014. "Vocal Fry May Undermine the Success of Young Women in the Labor Market." PloS One 9 (5): e97506.

Apple, William, Lynn Streeter, and Robert Krauss. 1979. "Effects of Pitch and Speech Rate on Personal Attributions." Journal of Personality and Social Psychology 37 (5): 715-27.

Banse, Rainer, and Klaus Scherer. 1996. "Acoustic Profiles in Vocal Emotion Expression." Journal of Personality and Social Psychology 70 (3): 614-36.

Bayley, Paul. 2004. Cross-Cultural Perspectives on Parliamentary Discourse. Amsterdam: John Benjamins Publishing.

Beck, Christina. 1996. “'I've Got Some Points I'd Like to Make Here': The Achievement of Social Face through Turn Management during the 1992 Vice Presidential Debate." Political Communication 13 (2): 165-80.

Behr, Roy, and Shanto Iyengar. 1985. "Television News, Real-World Cues, and Changes in the Public Agenda." Public Opinion Quarterly 49 (1): 38-57.

Benoit, William. 2013. Political Election Debates: Informing Voters about Policy and Character. Lanham, MD: Lexington Books.

Benoit, William, Joseph Blaney, and P. M. Pier. 1998. Campaign '96: A Functional Analysis of Acclaiming, Attacking, and Defending. Westport, CT: Greenwood.

Benoit, Kenneth, Kohei Watanabe, Haiyan Wang, Paul Nulty, Adam Obeng, Stefan Müller, and Akitaka Matsuo. 2018. "quanteda: An R Package for the Quantitative Analysis of Textual Data." The Journal of Open Source Software 3 (30): 774.

Black, Ryan C., Rachel A. Schutte, and Timothy R. Johnson. 2013. "Trying to Get What You Want: Heresthetical Maneuvering and US Supreme Court Decision Making." Political Research Quarterly 66 (4): 819-30.

Black, Ryan, Maron Sorenson, and Timothy Johnson. 2013. "Toward an Actor-Based Measure of Supreme Court Case Salience: Information-Seeking and Engagement during Oral Arguments." Political Research Quarterly 66 (4): 804-18.

Black, Ryan, Sarah Treul, Timothy Johnson, and Jerry Goldman. 2011. "Emotions, Oral Arguments, and Supreme Court Decision Making." Journal of Politics 73 (2): 572-81.

Bligh, Michelle, Jennifer Merolla, Jean Reith Schroedel, and Randall Gonzalez. 2010. "Finding Her Voice: Hillary Clinton's Rhetoric in the 2008 Presidential Campaign." Women's Studies 39 (8): 823-50.

Boydstun, Amber, Rebecca Glazier, Matthew Pietryka, and Philip Resnik. 2014. "Real-Time Reactions to a 2012 Presidential Debate: A Method for Understanding Which Messages Matter." Public Opinion Quarterly 78 (S1): 330-43.

Brader, Ted. 2006. Campaigning for Hearts and Minds: How Emotional Appeals in Political Ads Work. Chicago: University of Chicago Press.

Breyer, Stephen. 1998. "The Work of the Supreme Court." Bulletin of the American Academy of Arts and Sciences 52 (1): 47-58.
Brown, Bruce, William Strong, and Alvin Rencher. 1974. "Fifty-Four Voices from Two: The Effects of Simultaneous Manipulations of Rate, Mean Fundamental Frequency, and Variance of Fundamental Frequency on Ratings of Personality from Speech.' The Journal of the Acoustical Society of America 55 (2): 313-8.

Burgoon, Judee, Thomas Birk, and Michael Pfau. 1990. "Nonverbal Behaviors, Persuasion, and Credibility." Human Communication Research 17 (1): 140-69.

Carlson, David, and Jacob Montgomery. 2017. "A Pairwise Comparison Framework for Fast, Flexible, and Reliable Human Coding of Political Texts." American Political Science Review 111 (4): $835-43$

Carney, Dana, Judith Hall, and Lavonia LeBeau. 2005. "Beliefs about the Nonverbal Expression of Social Power." Journal of Nonverbal Behavior 29 (2): 105-23.

Cohen, Jeffrey. 1995. "Presidential Rhetoric and the Public Agenda." American Journal of Political Science 39 (1): 87-107.

Conroy-Krutz, Jeffrey, and Devra Moehler. 2015. "Moderation from Bias: A Field Experiment on Partisan Media in a New Democracy." The Journal of Politics 77 (2): 575-87.

Conway III, Lucian, Laura Gornick, Chelsea Burfeind, Paul Mandella, Andrea Kuenzli, Shannon Houck, and Deven Fullerton. 2012. "Does Complex or Simple Rhetoric Win Elections? An Integrative Complexity Analysis of US Presidential Campaigns." Political Psychology 33 (5): 599-618.

Cornell, Legal Information Institute. 2015. “Oyez Project.” Accessed November 17, 2020. https://www.oyez.org/.

Dancey, Logan, and Paul Goren. 2010. "Party Identification, Issue Attitudes, and the Dynamics of Political Debate." American Journal of Political Science 54 (3): 686-99.

Degani, Marta. 2015. Framing the Rhetoric of a Leader: An Analysis of Obama's Election Campaign Speeches. London: Palgrave Macmillan.

Dellaert, Frank, Thomas Polzin, and Alex Waibel. 1996. "Recognizing Emotion in Speech." In Proceedings of the Fourth International Conference on Spoken Language Processing. ICSLP '96. Philadelphia, PA: IEEE, 1970-3. doi: 10.1109/ICSLP.1996.608022.

Dietrich, Bryce, Ryan Enos, and Maya Sen. 2019. "Emotional Arousal Predicts Voting on the US Supreme Court." Political Analysis 27 (2): 237-43.

Dietrich, Bryce, Matthew Hayes, and Diana O'Brien. 2019. "Pitch Perfect: Vocal Pitch and the Emotional Intensity of Congressional Speech.” American Political Science Review 113 (4): 941-62.

Dietrich, Bryce, Dan Schultz, and Tracey Jaquith. 2018. "This Floor Speech Will Be Televised: Understanding the Factors that Influence When Floor Speeches Appear on Cable Television." Working Paper.

El Ayadi, Moataz, Mohamed Kamel, and Fakhri Karray. 2011. "Survey on Speech Emotion Recognition: Features, Classification Schemes, and Databases." Pattern Recognition 44: 572-87.

Epstein, Lee, William Landes, and Richard Posner. 2010. "Inferring the Winning Party in the Supreme Court from the Pattern of Questioning at Oral Argument." Journal of Legal Studies 39 (2): 433-67.

Epstein, Lee, William Landes, and Richard Posner. 2013. The Behavior of Federal Judges: A Theoretical and Empirical Study of Rational Choice. Cambridge, MA: Harvard University Press.

Fearon, James. 1994. "Domestic Political Audiences and the Escalation of International Disputes." American Political Science Review 88 (3): 577-92.

Fridkin, Kim, and Patrick Kenney. 2011. "Variability in Citizens' Reactions to Different Types of Negative Campaigns." American Journal of Political Science 55 (2): 307-25.

Fridkin, Kim, Patrick Kenney, Sarah Gershon, Karen Shafer, and Gina Woodall. 2007. "Capturing the Power of a Campaign Event: The 2004 Presidential Debate in Tempe." Journal of Politics 69 (3): $770-85$.

Galloway, Russell. 1989. "Oral Argument in the Court.” Trial 25 (1): 78-84.

Gregory Jr., Stanford, and Timothy Gallagher. 2002. "Spectral Analysis of Candidates' Nonverbal Vocal Communication: Predicting US Presidential Election Outcomes." Social Psychology Quarterly 65 (3): 298-308.

Grimmer, Justin, and Brandon Stewart. 2013. "Text as Data: The Promise and Pitfalls of Automatic Content Analysis Methods for Political Texts." Political Analysis 21 (3): 267-97. 
Guisinger, Alexandra, and Alastair Smith. 2002. "Honest Threats: The Interaction of Reputation and Political Institutions in International Crises." Journal of Conflict Resolution 46 (2): 175-200.

Hamilton, Mark, and Becky Stewart. 1993. "Extending an Information Processing Model of Language Intensity Effects." Communication Quarterly 41 (2): 231-46.

Hart, Roderick, and Sharon Jarvis. 1997. "Political Debate: Forms, Styles, and Media." American Behavioral Scientist 40 (8): 1095-122. Herzog, Alexander, and Kenneth Benoit. 2015. "The Most Unkindest Cuts: Speaker Selection and Expressed Government Dissent during Economic Crisis." The Journal of Politics 77 (4): 1157-75.

Hetherington, Marc. 1999. "The Effect of Political Trust on the Presidential Vote, 1968-96." American Political Science Review 93 (2): 311-26.

Hinck, Edward, and Shelly Hinck. 2002. "Politeness Strategies in the 1992 Vice Presidential and Presidential Debates." Argumentation and Advocacy 38 (4): 234-50.

Hodges-Simeon, Carolyn, Steven Gaulin, and David Puts. 2010. "Different Vocal Parameters Predict Perceptions of Dominance and Attractiveness." Human Nature 21 (4): 406-27.

Hofstetter, Richard, David Barker, James Smith, Gina Zari, and Thomas Ingrassia. 1999. "Information, Misinformation, and Political Talk Radio." Political Research Quarterly 52 (2): 353-69.

Iaryczower, Matias, Xiaoxia Shi, and Matthew Shum. 2018. "Can Words Get in the Way? The Effect of Deliberation in Collective Decision Making." Journal of Political Economy 126 (2): 688-734.

Iaryczower, Matias, and Matthew Shum. 2012. "The Value of Information in the Court: Get It Right, Keep It Tight." American Economic Review 102 (1): 202-37.

Johnson, Timothy. 2001. "Information, Oral Arguments, and Supreme Court Decision Making." American Politics Research 29 (4): 331-51.

Johnson, Timothy, and Jerry Goldman. 2009. "The Role of Oral Arguments in the Supreme Court." In A Good Quarrel: America's Top Legal Reporters Share Stories, eds. Timothy R. Johnson and Jerry Goldman, 1-11. Ann Arbor: University of Michigan Press.

Johnson, Timothy, Paul Wahlbeck, and James Spriggs. 2006. "The Influence of Oral Arguments on the U.S. Supreme Court." American Political Science Review 100 (1): 99-113.

Johnstone, Tom, and Klaus Scherer. 2000. "Vocal Communication of Emotion." Handbook of Emotions 2: 220-35.

Kappas, Arvid, Ursula Hess, and Klaus Scherer. 1991. "Voice and Emotion." In Fundamentals of Nonverbal Behavior, eds. Robert S. Feldman and Bernard Rimé, 200-38. Cambridge: Cambridge University Press.

Kaufman, Aaron, Peter Kraft, and Maya Sen. 2018. "Improving Supreme Court Forecasting Using Boosted Decision Trees." Political Analysis 27 (3): 381-7.

Kernell, Samuel. 2006. Going Public: New Strategies of Presidential Leadership. Washington, DC: CQ Press.

Klofstad, Casey. 2016. "Candidate Voice Pitch Influences Election Outcomes." Political Psychology 37 (5): 725-38.

Klofstad, Casey, Rindy Anderson, and Stephen Nowicki. 2015. "Perceptions of Competence, Strength, and Age Influence Voters to Select Leaders with Lower-Pitched Voices." PloS One 10 (8): e0133779.

Klofstad, Casey, Rindy Anderson, and Susan Peters. 2012. "Sounds Like a Winner: Voice Pitch Influences Perception of Leadership Capacity in Both Men and Women." Proceedings of the Royal Society B: Biological Sciences 279 (1738): 2698-704.

Kwon, Oh-Wook, Kwokleung Chan, Jiucang Hao, and Te-Won Lee. 2003. "Emotion Recognition by Speech Signals." In Eighth European Conference on Speech Communication and Technology. (EUROSPEECH 2003-INTERSPEECH 2003), Geneva, September 1-4. Available at ISCA Archive, http://www.iscaspeech.org/archive/eurospeech_2003.

Lauderdale, Benjamin, and Alexander Herzog. 2016. "Measuring Political Positions from Legislative Speech." Political Analysis 24 (3): 374-94.

Laustsen, Lasse, Michael Bang Petersen, and Casey Klofstad. 2015. "Vote Choice, Ideology, and Social Dominance Orientation Influence Preferences for Lower Pitched Voices in Political Candidates." Evolutionary Psychology 13 (3): 1474704915600576.
Laver, Michael, Kenneth Benoit, and John Garry. 2003. "Extracting Policy Positions from Political Texts Using Words as Data." American Political Science Review 97 (2): 311-31.

Leathers, Dale. 1979. "The Impact of Multichannel Message Inconsistency on Verbal and Nonverbal Decoding Behaviors." Communications Monographs 46 (2): 88-100.

Levi, Margaret, and Laura Stoker. 2000. "Political Trust and Trustworthiness." Annual Review of Political Science 3 (1): 475-507.

Lucas, Christopher, Richard Nielsen, Margaret Roberts, Brandon Stewart, Alex Storer, and Dustin Tingley. 2015. "ComputerAssisted Text Analysis for Comparative Politics." Political Analysis 23 (2): 254-77.

Manstead, Anthony, Hugh Wagner, and Christopher MacDonald. 1984. "Face, Body, and Speech as Channels of Communication in the Detection of Deception." Basic and Applied Social Psychology 5 (4): 317-32.

Manusov, Valerie, and April Trees. 2002. "“Are You Kidding Me?' The Role of Nonverbal Cues in the Verbal Accounting Process." Journal of Communication 52 (3): 640-56.

Martin, Andrew, and Kevin Quinn. 2002. "Dynamic Ideal Point Estimation via Markov Chain Monte Carlo for the U.S. Supreme Court, 1953-1999." Political Analysis 10 (2): 134-53.

McGilloway, Sinéad, Roddy Cowie, Ellen Douglas-Cowie, Stan Gielen, Machiel Westerdijk, and Sybert Stroeve. 2000.

"Approaching Automatic Recognition of Emotion from Voice: A Rough Benchmark." In ISCA Tutorial and Research Workshop (ITRW) on Speech and Emotion, Newcastle, September 5-7. Available at ISCA Archive, http://www.isca-speech.org/archive_ open/speech_emotion.

McGuire, Kevin. 1995. "Repeat Players in the Supreme Court: The Role of Experienced Lawyers in Litigation Success." Journal of Politics 57 (1): 187-96.

McKinney, Mitchell, Lynda Kaid, and Terry Robertson. 2001. "The Front-Runner, Contenders, and Also-Rans: Effects of Watching a 2000 Republican Primary Debate." American Behavioral Scientist 44 (12): 2232-51.

Mermin, Jonathan. 1997. "Television News and American Intervention in Somalia: The Myth of a Media-Driven Foreign Policy." Political Science Quarterly 112 (3): 385-403.

Mower, Emily, Angeliki Metallinou, Chi-Chun Lee, Abe Kazemzadeh, Carlos Busso, Sungbok Lee, and Shrikanth Narayanan. 2009. "Interpreting Ambiguous Emotional Expressions." In Proceedings ACII Special Session: Recognition of Non-Prototypical Emotion From Speech-The Final Frontier? 662-9.

Neal, Radford, and Geoffrey Hinton. 1998. "A View of the EM Algorithm That Justifies Incremental, Sparse, and Other Variants." In Learning in Graphical Models, ed. Michael I. Jordan, 355-68. Boston: Kluwer Academic Publishers.

Nogueiras, Albino, Asunción Moreno, Antonio Bonafonte, and José B Mariño. 2001. "Speech Emotion Recognition Using Hidden Markov Models." In Seventh European Conference on Speech Communication and Technology, 2267-70.

Oegema, Dirk, and Jan Kleinnijenhuis. 2000. "Personalization in Political Television News: A 13-Wave Survey Study to Assess Effects of Text and Footage." Communications 25 (1): 43-60.

Ohala, John. 1981. "The Listener as a Source of Sound Change." In Papers from the Parasession on Language Behavior, eds. Carrie S. Masek, Robert A. Hendrick, and Mary Frances Miller, 178-203. Chicago: Chicago Linguistic Society.

Olson, Jeremiah, Yu Ouyang, John Poe, Austin Trantham, and Richard Waterman. 2012. "The Teleprompter Presidency: Comparing Obama's Campaign and Governing Rhetoric." Social Science Quarterly 93 (5): 1402-23.

Podesva, Robert, Jermay Reynolds, Patrick Callier, and Jessica Baptiste. 2015. "Constraints on the Social Meaning of Released/T: A Production and Perception Study of US Politicians." Language Variation and Change 27 (1): 59-87.

Proksch, Sven-Oliver, and Jonathan Slapin. 2012. "Institutional Foundations of Legislative Speech." American Journal of Political Science 56 (3): 520-37.

Proksch, Sven-Oliver, and Jonathan Slapin. 2015. The Politics of Parliamentary Debate: Parties, Rebels and Representation. New York: Cambridge University Press.

Quinn, Kevin, Burt Monroe, Michael Colaresi, Michael Crespin, and Dragomir Radev. 2010. "How to Analyze Political Attention with 
Minimal Assumptions and Costs." American Journal of Political Science 54 (1): 209-28.

Ramirez, Mark D. 2009. "The Dynamics of Partisan Conflict on Congressional Approval." American Journal of Political Science 53 (3): 681-94.

Ringsmuth, Eve, Amanda Bryan, and Timothy Johnson. 2013. "Voting Fluidity and Oral Argument on the U.S. Supreme Court." Political Research Quarterly 66 (2): 429-40.

Ritter, Kurt, and Buddy Howell. 2001. "Ending the 2000 Presidential Election: Gore's Concession Speech and Bush's Victory Speech." American Behavioral Scientist 44 (12): 2314-30.

Roberts, Margaret, Brandon Stewart, Dustin Tingley, Christopher Lucas, Jetson Leder-Luis, Shana Kushner Gadarian, Bethany Albertson, and David Rand. 2014. "Structural Topic Models for Open-Ended Survey Responses." American Journal of Political Science 58 (4): 1064-82.

Rohde, David, and Harold Spaeth. 1976. Supreme Court Decision Making. New York: W. H. Freeman.

Ross, Scott. 2016. "Encouraging Rebel Demobilization by Radio in Uganda and the D. R. Congo: The Case of 'Come Home' Messaging." African Studies Review 59 (1): 33-55.

Rozenas, Arturas, and Denis Stukal. 2019. "How Autocrats Manipulate Economic News: Evidence from Russia's StateControlled Television." The Journal of Politics 81 (3): 982-96.

Rule, Alix, Jean-Philippe Cointet, and Peter Bearman. 2015. "Lexical Shifts, Substantive Changes, and Continuity in State of the Union Discourse, 1790-2014." Proceedings of the National Academy of Sciences 112 (35): 10837-44.

Sanders, David, and Neil Gavin. 2004. "Television News, Economic Perceptions and Political Preferences in Britain, 1997-2001." The Journal of Politics 66 (4): 1245-66.

Savage, David. 2009. "Rapanos v. United States: Wading into the Wetlands." In A Good Quarrel: America's Top Legal Reporters Share Stories, eds. Timothy R. Johnson and Jerry Goldman, 125-144. Ann Arbor: University of Michigan Press.

Scherer, Klaus. 1995. "Expression of Emotion in Voice and Music." Journal of Voice 9 (3): 235-48.

Scherer, Klaus. 2003. "Vocal Communication of Emotion: A Review of Research Paradigms." Speech Communication 40 (1-2): 227-56.

Scherer, Klaus, Judy Koivumaki, and Robert Rosenthal. 1972. "Minimal Cues in the Vocal Communication of Affect: Judging Emotions from Content-Masked Speech.” Journal of Psycholinguistic Research 1 (3): 269-85.

Scherer, Klaus, Harvey London, and Jared Wolf. 1973. "The Voice of Confidence: Paralinguistic Cues and Audience Evaluation." Journal of Research in Personality 7 (1): 31-44.

Schirmer, Annett, Yenju Feng, Antarika Sen, and Trevor Penney. 2019. "Angry, Old, Male-and Trustworthy? How Expressive and Person Voice Characteristics Shape Listener Trust." PloS One 14 (1): e0210555.

Schroedel, Jean, Michelle Bligh, Jennifer Merolla, and Randall Gonzalez. 2013. "Charismatic Rhetoric in the 2008 Presidential Campaign: Commonalities and Differences." Presidential Studies Quarterly 43 (1): 101-28.

Schroeder, Juliana, and Nicholas Epley. 2015. "The Sound of Intellect: Speech Reveals a Thoughtful Mind, Increasing a Job Candidate's Appeal.” Psychological Science 26 (6): 877-91.

Schroeder, Juliana, and Nicholas Epley. 2016. "Mistaking Minds and Machines: How Speech Affects Dehumanization and Anthropomorphism." Journal of Experimental Psychology: General 145 (11): 1427-37.

Schwarz, Daniel, Denise Traber, and Kenneth Benoit. 2017. "Estimating Intra-Party Preferences: Comparing Speeches to Votes." Political Science Research and Methods 5 (2): 379-96.

Segal, Jeffrey, and Harold Spaeth. 1993. The Supreme Court and the Attitudinal Model. New York: Cambridge University Press.

Semetko, Holli, and Patti Valkenburg. 2000. "Framing European Politics: A Content Analysis of Press and Television News." Journal of Communication 50 (2): 93-109.

Shapiro, Stephen. 1984. "Oral Argument in the Supreme Court of the United States." Catholic University Law Review 33 (3): 529-54.

Shullman, Sarah. 2004. "The Illusion of Devil's Advocacy: How the Justices of the Supreme Court Foreshadow Their Decisions during Oral Argument." Journal of Appellate Practice and Process 6 (2): article 6 .
Slapin, Jonathan, and Sven-Oliver Proksch. 2008. "A Scaling Model for Estimating Time-Series Party Positions from Texts." American Journal of Political Science 52 (3): 705-22.

Smith, Bruce, Bruce Brown, William Strong, and Alvin Rencher. 1975. "Effects of Speech Rate on Personality Perception." Language and Speech 18 (2): 145-52.

Sobieraj, Sarah, and Jeffrey Berry. 2011. "From Incivility to Outrage: Political Discourse in Blogs, Talk Radio, and Cable News." Political Communication 28 (1): 19-41.

Sotomayor, Sonia. 2019. "Life as a Supreme Court Justice." Interview with Trevor Noah.

Spaeth, Harold, Lee Epstein, Ted Ruger, Keith Whittington, Jeffrey Segal, and Andrew Martin. 2014. Supreme Court Database Code Book." scdb.wustl.edu.

Spiliotes, Constantine, and Lynn Vavreck. 2002. "Campaign Advertising: Partisan Convergence or Divergence?" The Journal of Politics 64 (1): 249-61.

Stern, Robert, Eugene Gressman, and Stephen Shapiro. 1993. Supreme Court Practice: For Practice in the Supreme Court of the United States. Washington, DC: Bureau of National Affairs.

Surawski, Melissa, and Elizabeth Ossoff. 2006. "The Effects of Physical and Vocal Attractiveness on Impression Formation of Politicians." Current Psychology 25 (1): 15-27.

Thomas, Clarence. 2013. "Lecture at Harvard Law School.” Accessed April 2019. https://www.youtube.com/watch?vheQjKdHu1P4.

Thomas, Matt, Bo Pang, and Lillian Lee. 2006. "Get Out the Vote: Determining Support or Opposition from Congressional FloorDebate Transcripts." In Proceedings of the 2006 Conference on Empirical Methods in Natural Language Processing, 327-35. Stroudsburg, PA: Association for Computational Linguistics.

Tigue, Cara, Diana Borak, Jillian O'Connor, Charles Schandl, and David Feinberg. 2012. "Voice Pitch Influences Voting Behavior." Evolution and Human Behavior 33 (3): 210-6.

Touati, Paul. 1993. "Prosodic Aspects of Political Rhetoric." Department of Linguistics and Phonetics, Working Papers 41: 168-171. Lund.

van der Laan, Mark, Sandrine Dudoit, and Sunduz Keles. 2004. "Asymptotic Optimality of Likelihood-Based Cross-Validation." Statistical Applications in Genetics and Molecular Biology $3(1): 4$.

Ververidis, Imitrios, and Constantine Kotropoulos. 2006. "Emotional Speech Recognition: Resources, Features, and Methods." Speech Communication 48: 1162-81.

Wasby, Stephen, Anthony D'Amato, and Rosemary Metrailer. 1976 "The Functions of Oral Argument in the US Supreme Court." Quarterly Journal of Speech 62 (4): 410-22.

Whissell, Cynthia. 2009. "Using the Revised Dictionary of Affect in Language to Quantify the Emotional Undertones of Samples of Natural Language." Psychological Reports 105 (2): 509-21.

Wilkerson, John, and Andreu Casas. 2017. "Large-Scale Computerized Text Analysis in Political Science: Opportunities and Challenges." Annual Review of Political Science 20: 529-44.

Wolfson, Warren D. 2001. "Oral Argument: Does It Matter." Indiana Law Review 35: 451-6.

Wong, Wing Hung. 1986. "Theory of Partial Likelihood.” Annals of Statistics 14 (3): 88-123.

Young, Garry, and William Perkins. 2005. "Presidential Rhetoric, the Public Agenda, and the End of Presidential Television's 'Golden Age." The Journal of Politics 67 (4): 1190-205.

Young, Lori, and Stuart Soroka. 2012. "Affective News: The Automated Coding of Sentiment in Political Texts." Political Communication 29 (2): 205-31.

Zucchini, Walter, and Iain MacDonald. 2009. Hidden Markov Models for Time Series. Boca Raton, FL: CRC Press.

Zuckerman, Miron, Bella DePaulo, and Robert Rosenthal. 1981. "Verbal and Nonverbal Communication of Deception." In Advances in Experimental Social Psychology. Vol. 14, ed. Leonard Berkowitz, 1-59. Cambridge, MA: Academic Press.

Zuckerman, Miron, Richard DeFrank, Judith Hall, Deborah Larrance, and Robert Rosenthal. 1979. "Facial and Vocal Cues of Deception and Honesty." Journal of Experimental Social Psychology 15 (4): 378-96.

Zuckerman, Miron, and Robert Driver. 1989. "What Sounds Beautiful Is Good: The Vocal Attractiveness Stereotype." Journal of Nonverbal Behavior 13 (2): 67-82. 